\title{
Monocarboxylate Transporter 4 Regulates Glioblastoma Motility and Monocyte Binding Ability
}

\author{
Sheng-Wei Lai ${ }^{1}$, Hui-Jung Lin ${ }^{2}$, Yu-Shu Liu ${ }^{2}$, Liang-Yo Yang ${ }^{3,4, *}$ and Dah-Yuu Lu ${ }^{2,5, *(\mathbb{C}}$ \\ 1 Graduate Institute of Basic Medical Science, China Medical University, Taichung 40402, Taiwan; \\ wayson081024@gmail.com \\ 2 Department of Pharmacology, School of Medicine, China Medical University, Taichung 40402, Taiwan; \\ linzoe9260@gmail.com (H.-J.L.); yushuliu220@gmail.com (Y.-S.L.) \\ 3 Department of Physiology, School of Medicine, China Medical University, Taichung 40402, Taiwan \\ 4 Laboratory for Neural Repair and Research Center for Biotechnology, China Medical University Hospital, \\ Taichung 40447, Taiwan \\ 5 Department of Photonics and Communication Engineering, Asia University, Taichung 41354, Taiwan \\ * Correspondence: yangly@mail.cmu.edu.tw (L.-Y.Y.); dahyuu@mail.cmu.edu.tw (D.-Y.L.); \\ Tel.: +886-4-2205-3366 (ext. 2253) (D.-Y.L.)
}

Received: 5 December 2019; Accepted: 5 February 2020; Published: 7 February 2020

\begin{abstract}
Glioblastoma (GBM) is characterized by severe hypoxic and acidic stress in an abnormal microenvironment. Monocarboxylate transporter (MCT)4, a pH-regulating protein, plays an important role in $\mathrm{pH}$ homeostasis of the glycolytic metabolic pathways in cancer cells. The present study showed that GBM exposure to hypoxic conditions increased MCT4 expression. We further analyzed the glioma patient database and found that MCT4 was significantly overexpressed in patients with GBM, and the MCT4 levels positively correlated with the clinico-pathological grades of gliomas. We further found that MCT4 knockdown abolished the hypoxia-enhanced of GBM cell motility and monocyte adhesion. However, the overexpression of MCT4 promoted GBM cell migration and monocyte adhesion activity. Our results also revealed that MCT4-regulated GBM cell motility and monocyte adhesion are mediated by activation of the serine/threonine-specific protein kinase (AKT), focal adhesion kinase (FAK), and epidermal growth factor receptor (EGFR) signaling pathways. Moreover, hypoxia mediated the acetylated signal transducer and activator of transcription (STAT)3 expression and regulated the transcriptional activity of hypoxia inducible factor (HIF)- $1 \alpha$ in GBM cell lines. In a GBM mouse model, MCT4 was significantly increased in the tumor necrotic tissues. These findings raise the possibility for the development of novel therapeutic strategies targeting MCT4.
\end{abstract}

Keywords: glioblastoma; hypoxic conditions; acidic microenvironment; MCT4; monocytes

\section{Introduction}

Glioblastoma (GBM) is the most common primary malignant brain tumor of all primary brain and central nervous system neoplasms [1,2]. Upon initial diagnosis of GBM, standard treatment consists of maximal surgical resection, radiotherapy, and adjuvant chemotherapy with temozolomide [3]. The highly heterogeneous tumor microenvironment plays a substantial role in treatment responses [4]. Histological studies have shown that GBM is one of the most hypoxic and angiogenic tumors $[5,6]$. GBM relies on robust intra-tumoral oxygenation and a pH-regulating system that leads to hypoxia and acidosis and the ability of tumor cells to adapt to the hypoxic microenvironment $[7,8]$, which offers a distinct evolutionary advantage towards an aggressive phenotype $[9,10]$.

Molecular mechanism responses to hypoxia are predominantly mediated by the transcriptional factor, hypoxia inducible factor (HIF)- $1 \alpha$ [11]. HIF- $1 \alpha$ is involved in the adaptive response under 
hypoxic conditions and in the regulation of many pivotal pathways in cancer [12,13]. Many recent studies have provided convincing evidence of strong correlations between elevated levels of HIF-1 $\alpha$ and tumor metastasis, angiogenesis, and tumor resistance to therapy [14-16]. Emerging evidence suggests that HIF- $1 \alpha$ inhibitors used in combination with standard chemotherapy improve the response of TMZ-resistant GBM cells [17]. Furthermore, silencing HIF-1 $\alpha$ expression appears to inhibit the proliferation [18], invasion, and migration of GBM [19]. Importantly, overexpression of HIF- $1 \alpha$ has been positively correlated with tumor progression and poor prognosis in patients with GBM [20,21].

Tumor cells produce increased amounts of $\mathrm{H}^{+}$including lactic and carbonic acids, owing to the enhanced metabolic rates [22,23]. In addition, many studies point to tumor hypoxia increasing the expression of $\mathrm{pH}$-regulating proteins that leads to acidosis of tumor microenvironments $[24,25]$. The resultant increased $\mathrm{H}^{+}$production, coupled with poor extracellular clearance, creates a hypoxic and acidic niche that could rapidly become lethal to cells [26]. The bi-directional monocarboxylate transporters (MCTs) perform $\mathrm{H}^{+}$-linked transport of l-lactate across the plasma membrane and thus contribute to pHi regulation $[27,28]$. The MCT family consists of fourteen members $[29,30]$; MCT4 is the only member with $\mathrm{H}^{+}$-dependent transporters of monocarboxylic acids [31,32]. Increasing reports show that expression of MCT4 has also been linked to poor prognosis in several cancers [33,34]. Malignant tumors overexpress MCT4, characteristic of metastatic cancer in association with HIF- $1 \alpha$ upregulation [35,36]. It has been shown that pharmacological or genetic ablation of MCT4 activity leads to reduced lung cancer cell proliferation [37]. Moreover, conditional MCT4 depletion efficiently inhibits tumor growth of glioma cancer stem cell (GSC)-derived xenografts [38]. Importantly, high expression of MCT4 has been positively correlated with tumor progression and poor prognosis in patients with GBM [39].

The present study showed that the activation of the epidermal growth factor receptor (EGFR) modulated HIF- $1 \alpha$ and MCT4 expression under hypoxic conditions. In addition, hypoxia-induced acetylation of the signal transducer and activator of transcription (STAT3) contributed to HIF-1 $\alpha$ and MCT4 expression, leading to GBM migration and monocyte adhesion. Furthermore, GBM-bearing mice also showed high expression of MCT4 in the tumor necrotic areas of GBM.

\section{Results}

\subsection{MCT4 Expression Correlates with Pathological Grades of Human Glioma}

It has been reported that hypoxia-induced HIF- $1 \alpha$ is a key factor in modulating the expression of $\mathrm{pH}$-regulating proteins [40]. As shown in Figure 1A, hypoxia induces HIF- $1 \alpha$ and MCT4 protein expression in a time-dependent manner in human GBM. Similar effects were observed in the mouse GBM ALTS1C1 (Figure 1A). Hypoxia further induced MCT4 (SLC16A3), but not HIF-1 $\alpha$ (HIF-1A) mRNA expression in a time-dependent manner (Figure 1B,C). $\mathrm{pH}$ measurement revealed significant acidification of the medium by GBM cells grown under hypoxic conditions (Figure 1D). We further analyzed the GSE4290 dataset showing that the mRNA levels of MCT4 were higher in the GBM group than in the astrocytoma groups (grade II and III). In addition, MCT4 levels were significantly higher in the GBM group than in the non-tumor group (Figure 1E).

\subsection{MCT4 Is Involved in the Hypoxia-Enhanced GBM Migration and Monocyte Adhesion}

It has been reported that MCT4 expression is correlated with malignancy in gliomas [39], and MCT4 elevation in GBM was also correlated with poor prognosis [41]. Based on a previous study and our earlier finding, we further investigated the role of MCT4 in the modulation of hypoxia in GBM. MCT4 mediated the binding of monocytes to GBM as determined by the monocyte-binding assay. As shown in Figure 2A-C, treatment of GBMs with the MCT4 inhibitor, CHC (a-cyano-4-hydroxycinnamic acid), decreased hypoxia-enhanced monocyte adhesion (green color; Figure 2A). In addition, a transwell assay was performed to further examine whether MCT4 facilitated GBM migration under hypoxic 
conditions. Treatment with CHC decreased the hypoxia-enhanced GBM migration activity in both of the human GBM cell lines, i.e., U87 and U251 (Figure 2D-F).

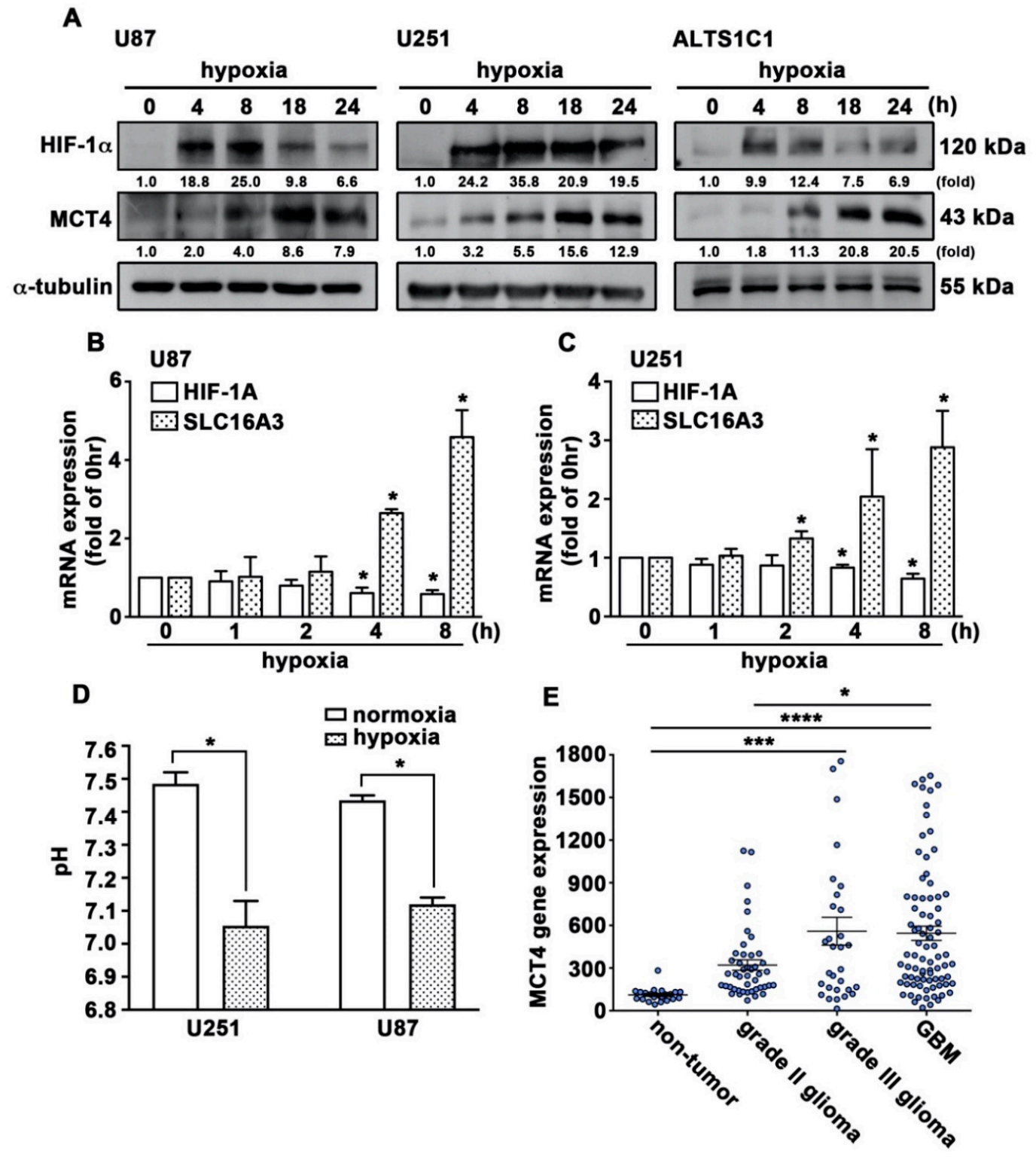

Figure 1. Hypoxia induces HIF-1 $\alpha$ and MCT4 expression in GBM. (A) Human GBM cell lines U87 and U251 and the mouse GBM cell line ALTS1C1 were exposed to hypoxic conditions $\left(1 \% \mathrm{O}_{2}\right)$ for indicated time periods $(4,8,18$, or $24 \mathrm{~h})$. HIF- $1 \alpha$ and MCT4 protein expressions were determined using western blotting. U87 (B) and U251 (C) were exposed to hypoxic conditions $\left(1 \% \mathrm{O}_{2}\right)$ for indicated time periods $(1,2,4$, or $8 \mathrm{~h})$, and HIF- $1 \alpha$, and MCT4 mRNA expression was determined by qPCR. One-way ANOVA with a post-hoc Bonferroni test was used to examine the significance of the mean. ${ }^{*} p<0.05$ compared with the control group. Quantitative data are presented as the mean \pm S.E.M. $(n=3)$. (D) pH measurements of culture medium $24 \mathrm{~h}$ after growing GBM cells under hypoxic conditions $\left(1 \% \mathrm{O}_{2}\right)$. ${ }^{*} p<0.05$ compared with the normoxia group (Student's $t$-test). Quantitative data are presented as the mean \pm S.E.M. $(n=3)$. (E) mRNA levels of MCT4 in patients' specimens from the human glioma microarray dataset GSE4290. One-way ANOVA with a post-hoc Bonferroni test was used to examine the significance of the mean. ${ }^{*} p<0.05$ GBM compared with grade II glioma. ${ }^{* * *} p<0.001$ grade III glioma compared with non-tumor. ${ }^{* * *} p<0.0001$ GBM compared with non-tumor. 

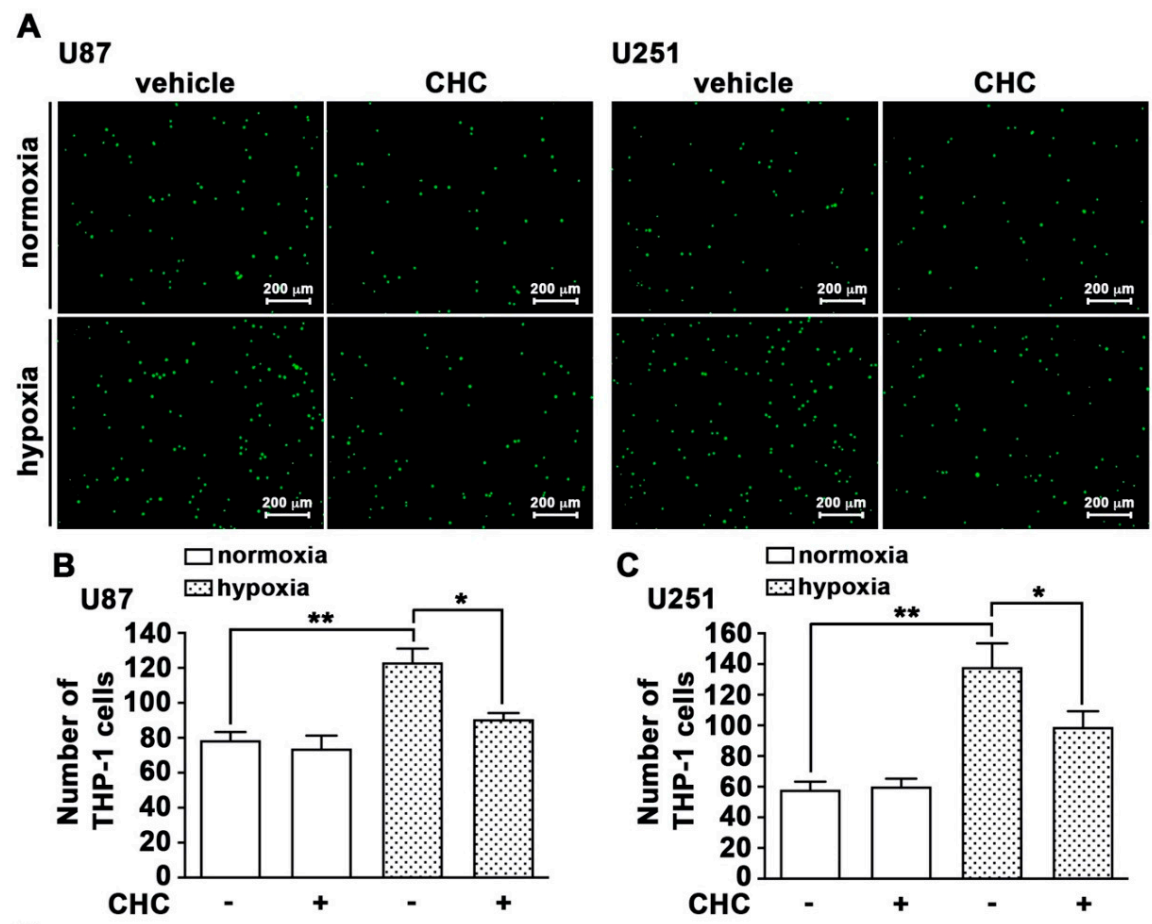

D $\mathbf{8 7}$

vehicle

CHC

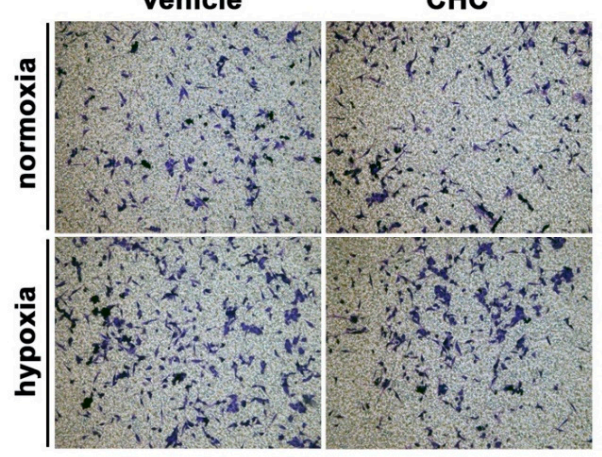

U251
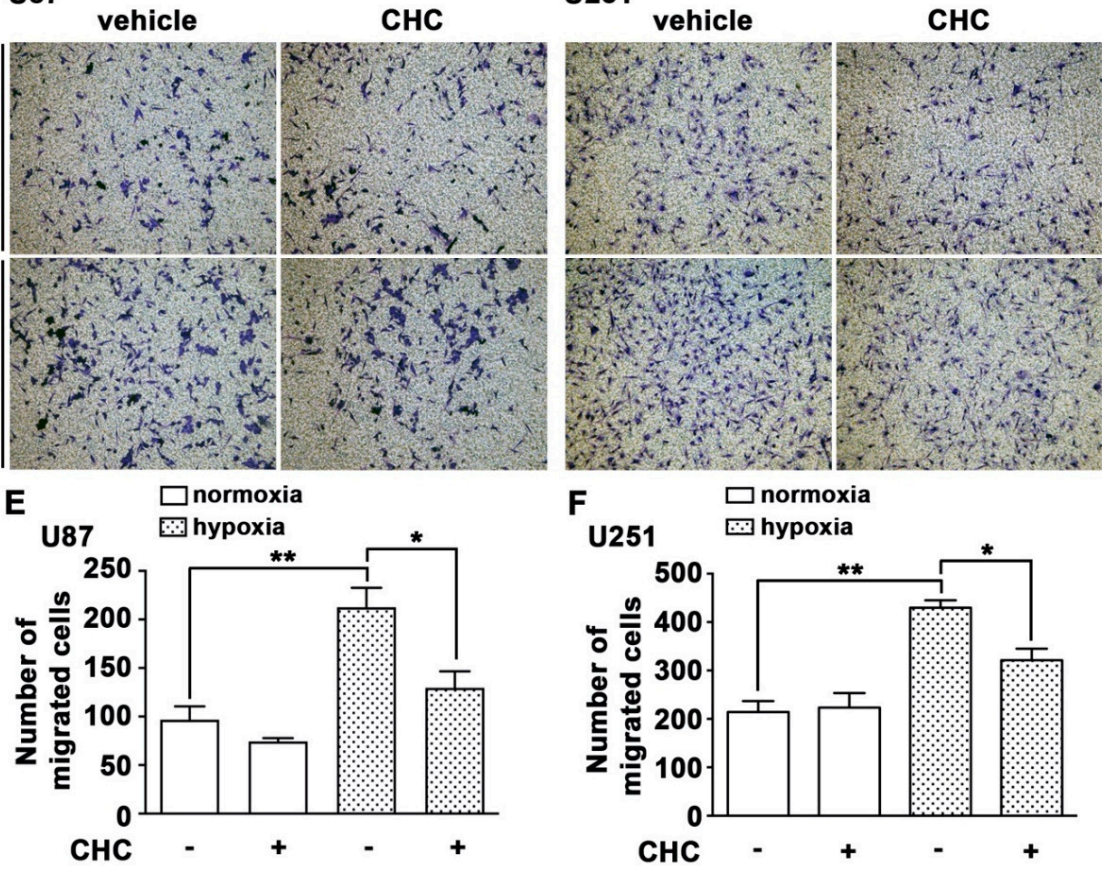

Figure 2. MCT4 is involved in hypoxia-enhanced monocyte adhesion and GBM migration. (A) U87 and U251 were treated with an MCT4 inhibitor (CHC; 1 or $2.5 \mathrm{mM}$ ) for $30 \mathrm{~min}$ and were exposed to hypoxic conditions $\left(1 \% \mathrm{O}_{2}\right)$ for $24 \mathrm{~h}$. BCECF-AM-labeled-THP-1 was added to U87 and U251 for $40 \mathrm{~min}$, and then the adherence of THP-1 was captured by fluorescence microscopy. Quantification of THP-1 monocyte adhesion abilities on GBM U87 (B) or U251 (C). (D) GBM U87 and U251 were treated with an MCT4 inhibitor (CHC; 1 or $2.5 \mathrm{mM}$ ) for $30 \mathrm{~min}$ and were exposed to hypoxic conditions $\left(1 \% \mathrm{O}_{2}\right)$, and the migration activities were measured after $24 \mathrm{~h}$ by a transwell assay and were visualized using a digital camera. Quantification of GBM U87 (E) and U251 (F) migration by number of cells that migrated to the underside of the membrane. Two-way ANOVA with a post-hoc Bonferroni test was used to examine the significance of the mean. ${ }^{*} p<0.05$ compared with the hypoxia-only group. ** $p<0.01$ compared with normoxia control group. 
Similar effects were observed using the genetic method, wherein the transfection with shRNA against MCT4 attenuated the hypoxia-enhanced monocyte adhesion (Figure 3A-C) and GBM migration activity (Figure 3D-F). The most aggressive cancers rely on a robust glycolysis system leading to increased formation of intracellular lactate, which is exported to the extracellular environment by MCT4 [42].

A
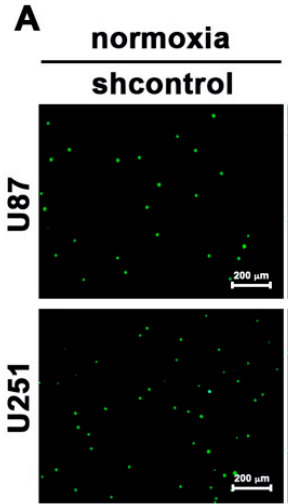

D

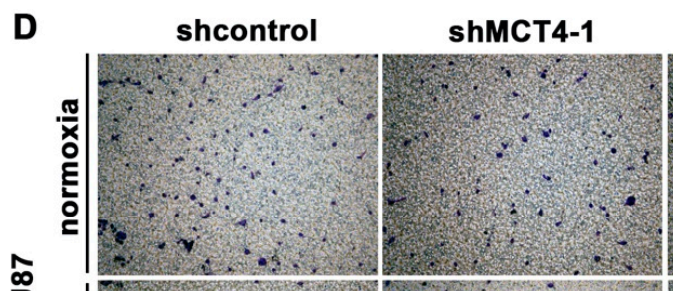

$\stackrel{\infty}{\supset}$
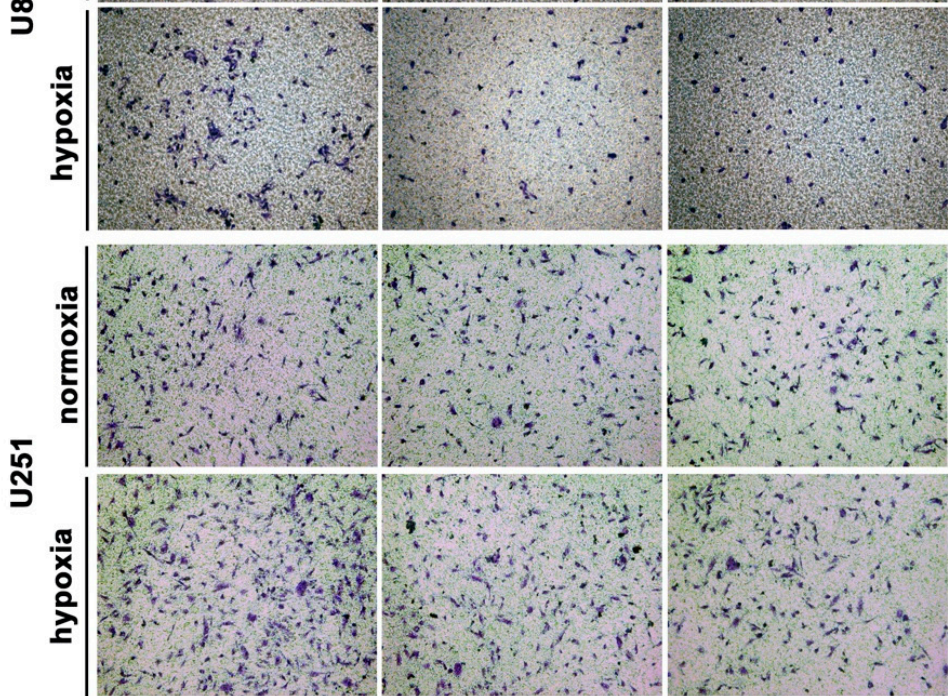

B

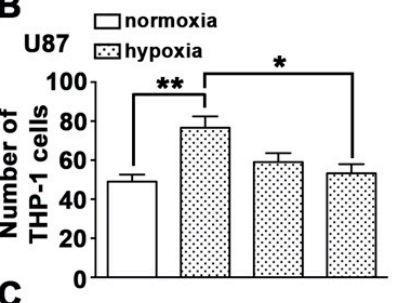

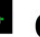

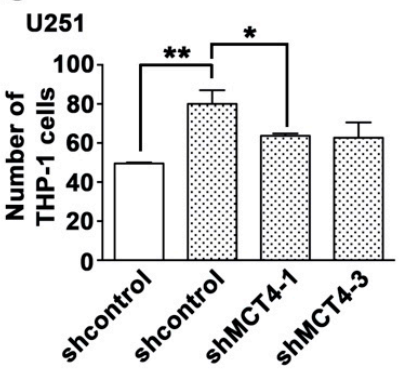

E

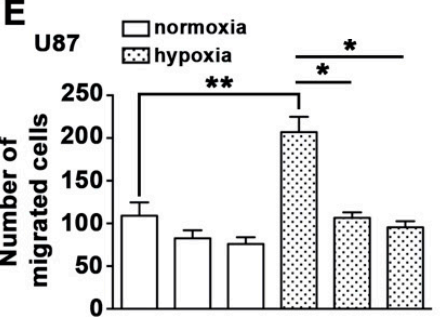

$F$

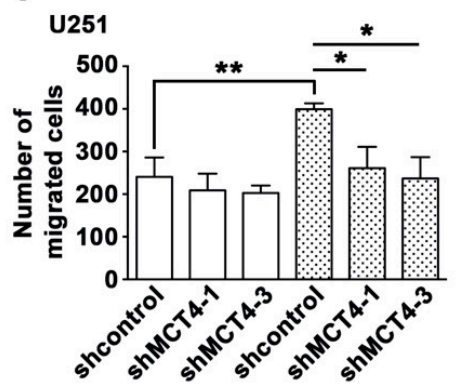

Figure 3. Downregulation of MCT4 attenuates hypoxia-enhanced monocyte adhesion and GBM migration. (A) U87 and U251 cells were transfected with the control or MCT4 shRNA for $24 \mathrm{~h}$ and were exposed to hypoxic conditions $\left(1 \% \mathrm{O}_{2}\right)$ for $24 \mathrm{~h}$. BCECF-AM-labeled-THP- 1 was added to U87 and U251 cells for $40 \mathrm{~min}$, and then the adherence of THP-1 was measured by fluorescence microscopy. Quantification of monocyte adhesion abilities on GBM U87 (B) or U251 (C) cells. (D) GBM U87 and U251 cells were transfected with the control or MCT4 shRNA for $24 \mathrm{~h}$ and were exposed to hypoxic conditions $\left(1 \% \mathrm{O}_{2}\right)$ for $24 \mathrm{~h}$; migration activities were measured by a transwell assay and were visualized using a digital camera. Quantification of U87 (E) and U251 (F) cell migration by counting the number of cells that migrated to the underside of the filter. Two-way ANOVA with a post-hoc Bonferroni multiple was used to examine the significance of the mean. ${ }^{*} p<0.05$ compared with the hypoxia control (sh) group. ** $p<0.01$ compared with the normoxia control (shcontrol) group. 
To evaluate the direct effects of MCT4 in hypoxia-induced extracellular acidosis, we showed that knockdown of MCT4 by shRNA reduced the acidified tumor medium (Figure S1A,B). However, transfection with the wild-type of MCT4 increased the GBM monocyte adhesion and migration activity in human GBM U87 and U251 cells (Figure 4A,B, Figure S2A). These results indicated that hypoxia-induced MCT4 expression markedly enhanced GBM-associated monocyte adhesion and GBM motility.
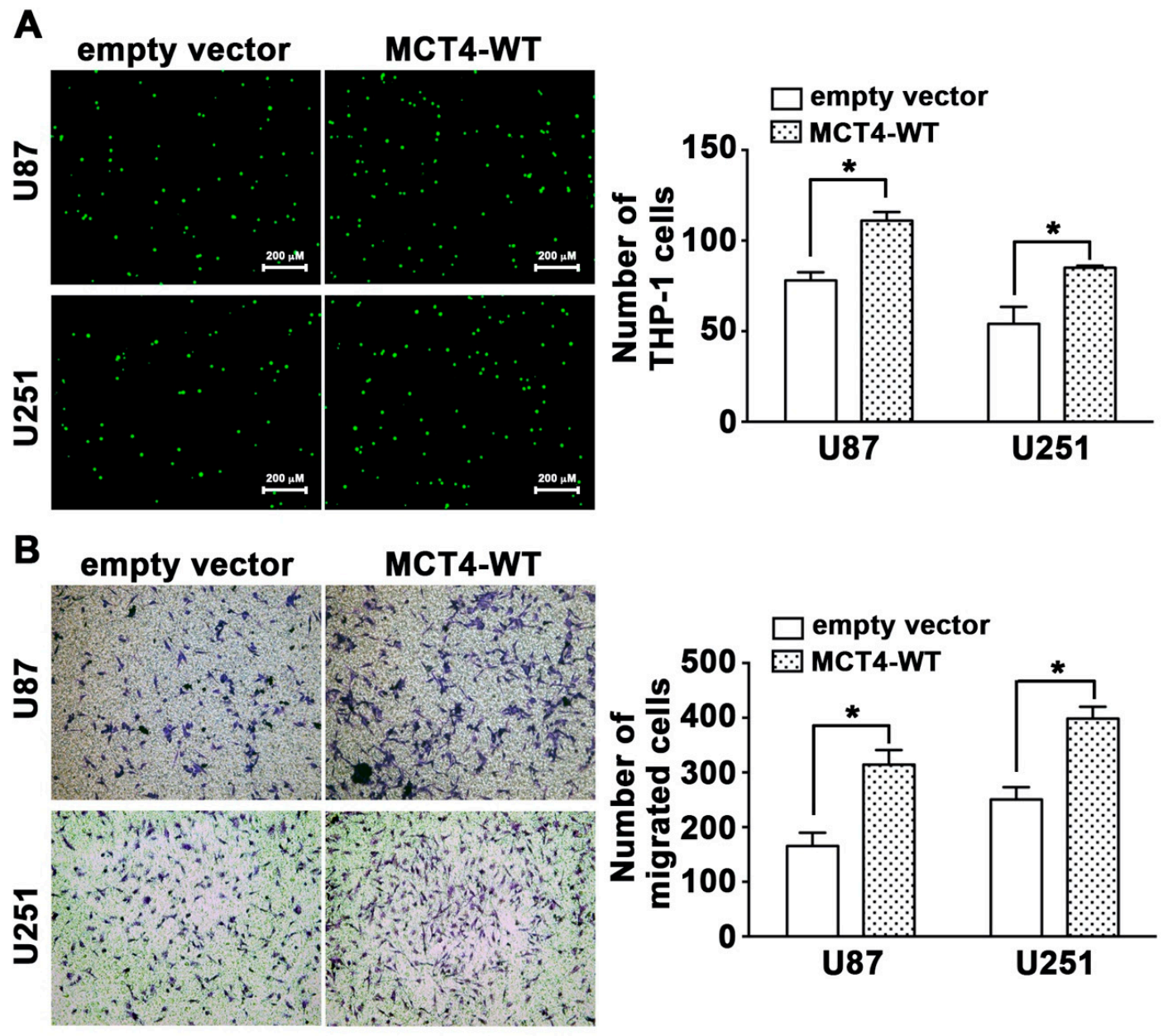

Figure 4. Overexpression of MCT4 enhances monocyte adhesion and GBM migration. U87 and U251 cells were transfected with either an empty vector or wild-type MCT4 for $24 \mathrm{~h}$ and were exposed to hypoxic conditions $\left(1 \% \mathrm{O}_{2}\right)$ for $24 \mathrm{~h}$. (A) quantification of monocyte adhesion ability (right panel) was quantified using fluorescence microscopy. (B) GBM migration activity (right panel) was quantified using a digital camera. ${ }^{*} p<0.05$ compared with the empty vector group (Student's $t$-test). Quantitative data are presented as the mean \pm S.E.M. $(n=3)$.

\subsection{HIF-1 $\alpha$ Is Involved in the Hypoxia-Induced MCT4 Expression in GBM}

Next, we further examined whether HIF-1 $\alpha$ modulated MCT4 expression under hypoxic conditions. As shown in Figure 5A, GBM treated with the HIF-1 $\alpha$ inhibitor showed decreased hypoxia-induced MCT4 expression. Additionally, GBM was first exposed to hypoxia-induced MCT4 transcription activity and then treated with the HIF-1 $\alpha$ inhibitor, which reversed the hypoxia-enhanced MCT4 expression (Figure 5B). Moreover, GBM was treated with an HIF-hydroxylase inhibitor DMOG (dimethyloxalylglycine) which can cause HIF-1 $\alpha$ protein stabilization. As shown in Figure 5C, DMOG dramatically increased HIF-1 $\alpha$ and MCT4 protein expressions under normoxia. We further analyzed GSE4290, of which the dataset showed that the levels of HIF-1 $\alpha$ were higher in the GBM group than 
in the astrocytoma groups (grade II and III). In addition, HIF-1 $\alpha$ levels were significantly higher in the GBM group than in the non-tumor group (Figure 5D). Notably, Pearson's correlation analysis also showed a positive correlation between HIF-1 $\alpha$ and MCT4 expression levels in the gene expression dataset of patients with glioma (Figure 5E). These data suggest that hypoxia stimulates HIF-1 $\alpha$ protein stabilization and subsequently increases MCT4 expression.

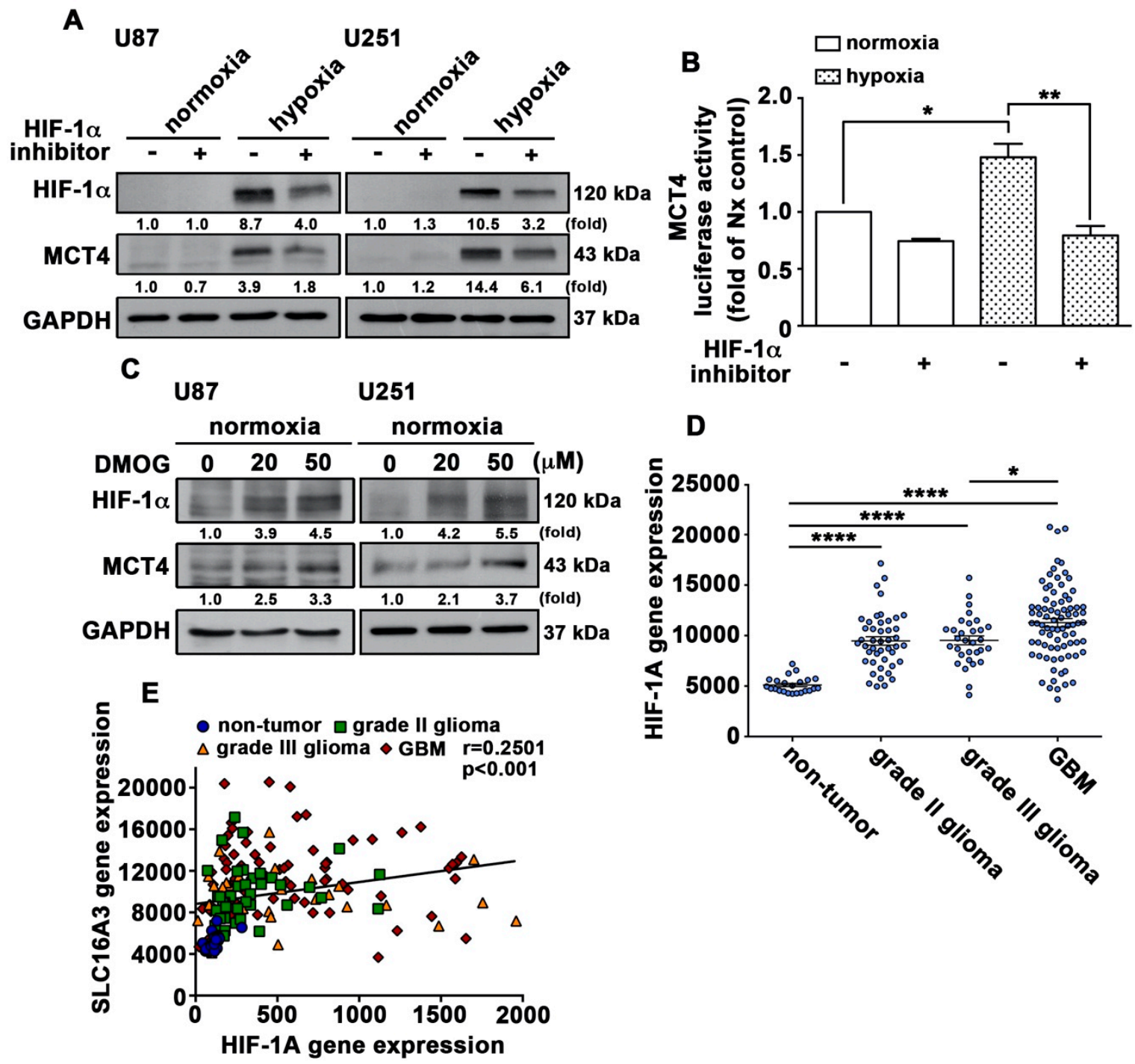

Figure 5. HIF- $1 \alpha$ is involved in hypoxia-induced MCT4 expression. (A) U87 and U251 cells were treated with the HIF- $1 \alpha$ inhibitor $(10 \mu \mathrm{M})$ for $30 \mathrm{~min}$ and were exposed to hypoxic conditions $\left(1 \% \mathrm{O}_{2}\right)$ for another $24 \mathrm{~h}$. (B) U251 cells were transfected with MCT4 luciferase reporter plasmids for $24 \mathrm{~h}$ and were treated with the HIF- $1 \alpha$ inhibitor $(10 \mu \mathrm{M})$ for $30 \mathrm{~min}$ and were then exposed to hypoxic conditions $\left(1 \% \mathrm{O}_{2}\right)$. Firefly luciferase activity was measured after $24 \mathrm{~h}$, and the results were normalized to renilla luciferase activity. Two-way ANOVA with a post-hoc Bonferroni test was used to examine the significance of the mean. ${ }^{*} p<0.05$ compared with the normoxia control group. ${ }^{* *} p<0.01$ compared with the hypoxia-only group. Quantitative data are presented as the mean \pm S.E.M. $(n=3)$. (C) U87 and ALTS1C1 cells were treated with DMOG $(20$, or $50 \mu \mathrm{M})$ for $24 \mathrm{~h}$. HIF- $1 \alpha$ and MCT4 protein expressions were determined using western blotting. (D) mRNA levels of $H I F-1 \alpha$ in patient specimens from the human glioma microarray dataset GSE4290. One-way ANOVA with a post-hoc Bonferroni test was used to examine the significance of the mean. ${ }^{*} p<0.05$ GBM compared with grade III glioma. **** $p<0.0001$ compared with non-tumor. (E) Pearson's correlation analysis between HIF-1 $\alpha$ and MCT4 gene expressions in the human glioma microarray dataset GSE4290 ( $\mathrm{r}=0.2501, p<0.001)$. 


\subsection{Acetylated STAT3 Is Involved in Hypoxia-Induced HIF-1 $\alpha$ and MCT4 Expression in GBM}

A previous study reported that tumor cell responses to hypoxia are predominantly mediated by HIF-1 $\alpha$, which transactivates more genes essential for adaptation and tumor survival $[43,44]$. As shown in Figure 6A, human GBM cells exposed to hypoxia resulted in the translocation of HIF-1 $\alpha$ from the cytoplasm to the nucleus. Moreover, GBM cells exposed to hypoxia showed increased HIF-1 $\alpha$ binding to the hypoxia response element (HRE) binding site on the MCT4 promoter (Figure 6B). On the other hand, the histone deacetylase (HDAC) inhibitor and histone acetyl transferases (HATs) are believed to promote transcription by enhancing acetylation of histones, transcription factors, and coactivators $[45,46]$. As shown in Figure 6C, treatment with the HDAC inhibitor (SAHA) increased hypoxia-induced HIF-1 $\alpha$ and MCT4 protein expressions in GBM cells. In addition, GBM cells incubated under hypoxic conditions showed increased STAT3 acetylation in a time-dependent manner (Figure 6D). Furthermore, inhibition of STAT3 by a STAT3 pharmacological inhibitor, stattic, effectively antagonized the hypoxia-induced HIF-1 $\alpha$ and MCT4 expressions in the human GBM U87 and U251 cell lines (Figure 6E). The above results indicated that post-translational modification of STAT3 was involved in the hypoxia-induced HIF-1 $\alpha$ and MCT4 expressions in GBM.

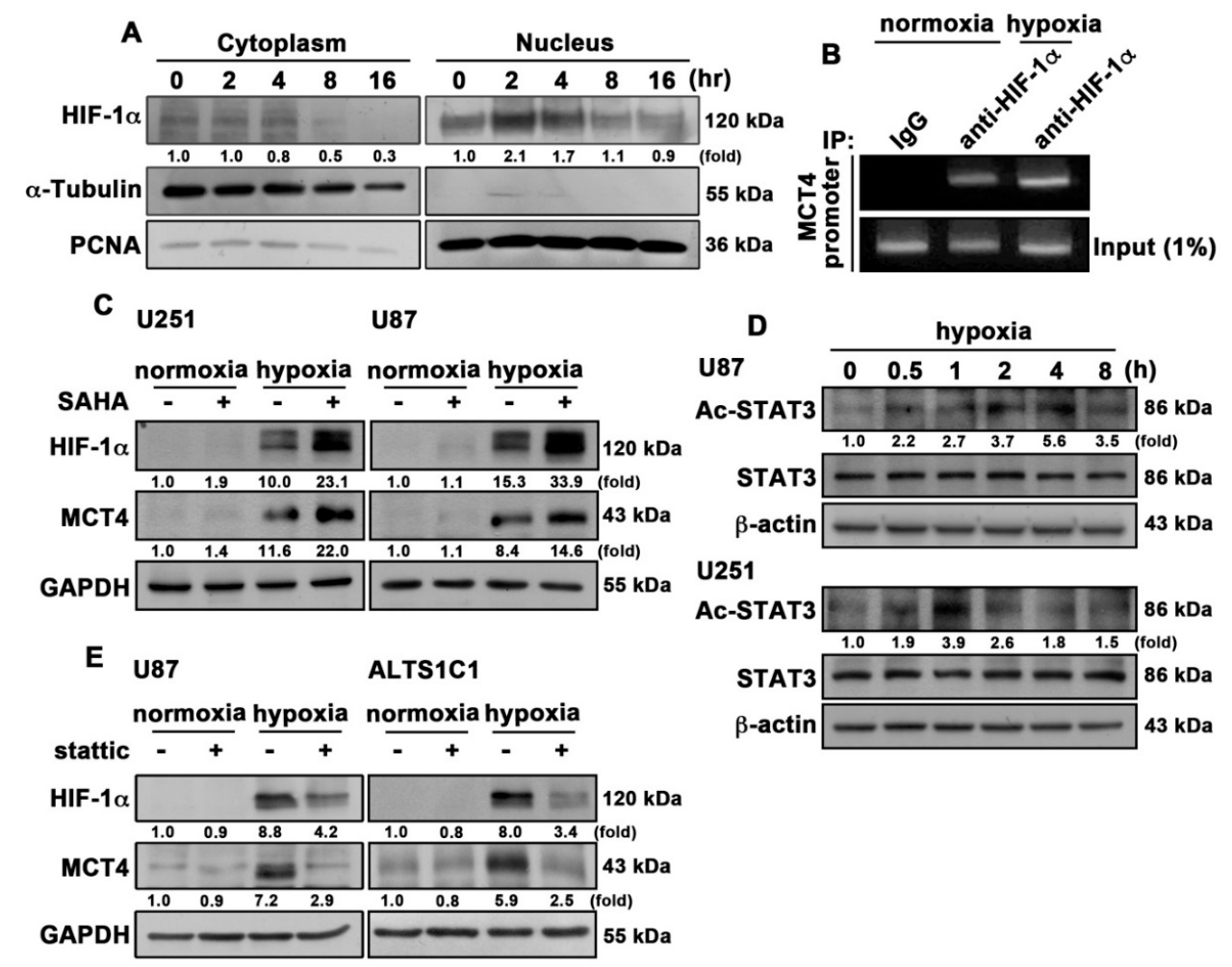

Figure 6. Acetylated STAT3 is involved in hypoxia-induced HIF- $1 \alpha$ and MCT4 expressions in GBM. (A) The cytosolic and nuclear extracts from hypoxia-induced $\left(1 \% \mathrm{O}_{2} ; 2,4,8\right.$ or $\left.16 \mathrm{~h}\right) \mathrm{U} 251$ cells were subjected to western blotting. Levels of HIF-1 $\alpha$ were determined. (B) U87 was exposed to hypoxic conditions $\left(1 \% \mathrm{O}_{2}\right)$ for $4 \mathrm{~h}$, and cells were then fixed and subjected to chromatin immunoprecipitation assay using antibodies against HIF-1 $\alpha$ or mouse IgG. Levels of immunoprecipitated chromatin fragments of the MCT4 promoter or input were examined by PCR. (C) U251 (left panel) and U87 (right panel) cells were treated with SAHA (HDAC inhibitor; $2 \mu \mathrm{M}$ ) for $30 \mathrm{~min}$ and were exposed to hypoxic conditions $\left(1 \% \mathrm{O}_{2}\right)$ for $24 \mathrm{~h}$. HIF- $1 \alpha$ and MCT4 expression levels were determined using western blotting. (D) U87 and U251 cells were exposed to hypoxic conditions $\left(1 \% \mathrm{O}_{2}\right)$ for indicated time periods $(0.5,1,2,4$ or $8 \mathrm{~h}$ ), and acetylated-STAT3 expression was determined using western blotting. (E) U87 (left panel) and ALTS1C1 (right panel) cells were treated with stattic (STAT3 inhibitor; $10 \mu \mathrm{M}$ ) for 30 min and were exposed to hypoxic conditions $\left(1 \% \mathrm{O}_{2}\right)$ for $24 \mathrm{~h}$. HIF- $1 \alpha$ and MCT4 expression levels were determined using western blotting. Quantitative data are presented as the mean \pm S.E.M. $(n=3)$. 


\subsection{Activation of FAK and AKT is Involved in Hypoxia-Induced HIF-1 $\alpha$ and MCT4 Expression in GBM}

Recent evidence suggests that focal adhesion kinase (FAK) and serine/threonine-specific protein kinase (AKT) could be dual kinase targets that prevent cancer cell adhesion and metastasis [47]. Our previous study indicated that bradykinin-induced IL-8 expression and GBM migration are mediated by the FAK/STAT3 signaling pathways [48]. Moreover, hypoxia increased cancer cell migration via HIF-mediated FAK phosphorylation [49]. As shown in Figure 7A, GBM cells exposed to hypoxic conditions increased FAK and AKT phosphorylation in a time-dependent manner. Next, we further investigated whether FAK and AKT were involved in HIF-1 $\alpha$-mediated MCT4 expression. Treatment with a FAK pharmacological inhibitor, PF573228, reduced the hypoxia-induced HIF- $1 \alpha$ and MCT4 expression in GBM (Figure 7B). Moreover, treatment with the PI3 kinase/AKT pharmacological inhibitor LY294002 also attenuated the hypoxia-induced HIF-1 $\alpha$ and MCT4 expression in GBM cells (Figure 7C). On the other hand, treatment with FAK or PI3 kinase/AKT inhibitors effectively reduced hypoxia-enhanced MCT4 transcription activity (Figure 7D). These results indicate that FAK and AKT signaling is an important effector of hypoxia-mediated stabilization of the expression of the HIF- $1 \alpha$ protein and MCT4 in GBM.

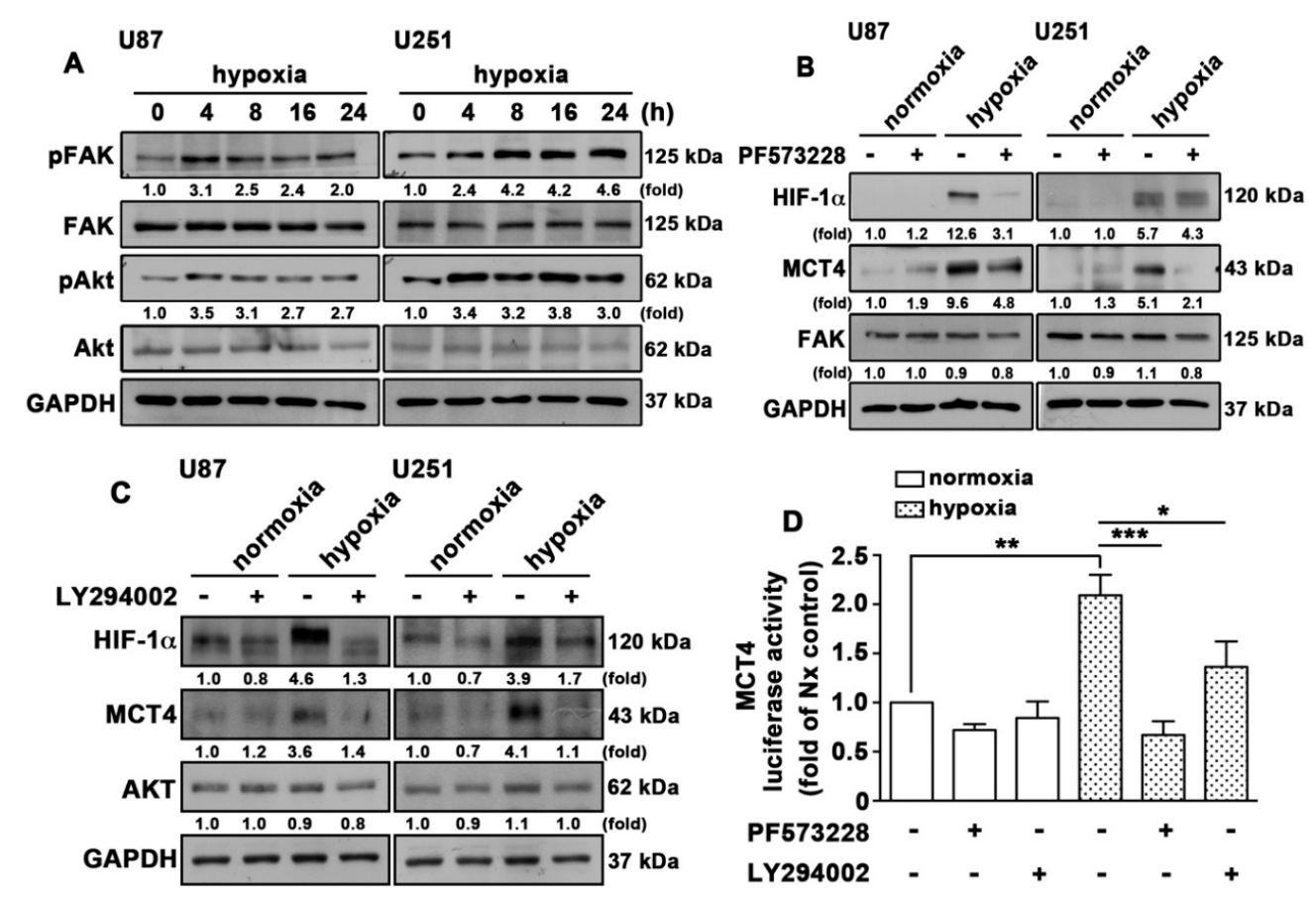

Figure 7. Activation of FAK and AKT is involved in the hypoxia-induced HIF- $1 \alpha$ and MCT4 expression in GBM. (A) U87 and U251 cells were exposed to hypoxic conditions $\left(1 \% \mathrm{O}_{2}\right)$ for indicated time periods $(4,8,16$ or $24 \mathrm{~h})$, and expression of p-FAK (Tyr397) and p-AKT (Ser473) was determined using western blotting. (B) U87 (left panel) and U251 (right panel) cells were treated with PF573228 $(2 \mu \mathrm{M})$ for $30 \mathrm{~min}$ and were exposed to hypoxic conditions $\left(1 \% \mathrm{O}_{2}\right)$ for another $24 \mathrm{~h}$. FAK, HIF-1 $\alpha$, and MCT4 expression was determined using western blotting. (C) U87 (left panel) and U251 (right panel) cells were treated with LY294002 $(10 \mu \mathrm{M})$ for $30 \mathrm{~min}$ and were exposed to hypoxic conditions $\left(1 \% \mathrm{O}_{2}\right)$ for another $24 \mathrm{~h}$. AKT, HIF-1 $\alpha$, and MCT4 expression was determined using western blotting. (D) U251 cells were transfected with MCT4 luciferase reporter plasmids for $24 \mathrm{~h}$ and were treated with PF573228 $(2 \mu \mathrm{M})$ or LY294002 $(10 \mu \mathrm{M})$ for $30 \mathrm{~min}$ and were then exposed to hypoxic conditions $\left(1 \% \mathrm{O}_{2}\right)$ for another $24 \mathrm{~h}$. Firefly luciferase activity was measured, and the results were normalized to renilla luciferase activity. Two-way ANOVA with a post-hoc Bonferroni test was used to examine the significance of the mean. ${ }^{*} p<0.05$ compared with the hypoxia-only group. ${ }^{* *} p<0.01$ compared with the normoxia control group. ${ }^{* * *} p<0.001$ compared with the hypoxia-only group. Quantitative data are presented as the mean \pm S.E.M. $(n=3)$. 


\subsection{Activation of EGFR Is Involved in Hypoxia-Induced HIF-1 $\alpha$ and MCT4 Expression in GBM}

It has been reported that amplification of EGFR and its active mutants occurs frequently in GBM [50] and is associated with a poor patient outcome and survival rate [51]. Our previous study also showed that STAT3 signaling was involved in the EGFR-associated adhesion molecule expression and monocyte adhesion in GBM [50]. We now investigated whether EGFR is involved in HIF-1 $\alpha$-mediated MCT4 expression. Treatment with EGFR tyrosine kinase inhibitors, erlotinib, gefitinib or AG1478, reduced the hypoxia-induced MCT4 expression in GBM (Figure 8A,B). Similarly, treatment with EGFR inhibitors significantly reduced hypoxia-enhanced MCT4 transcription activity (Figure 8C,D). These results indicated that EGFR signaling was an important effector of hypoxia-mediated stabilization of the HIF-1 $\alpha$ protein and MCT4 expression in GBM.

A
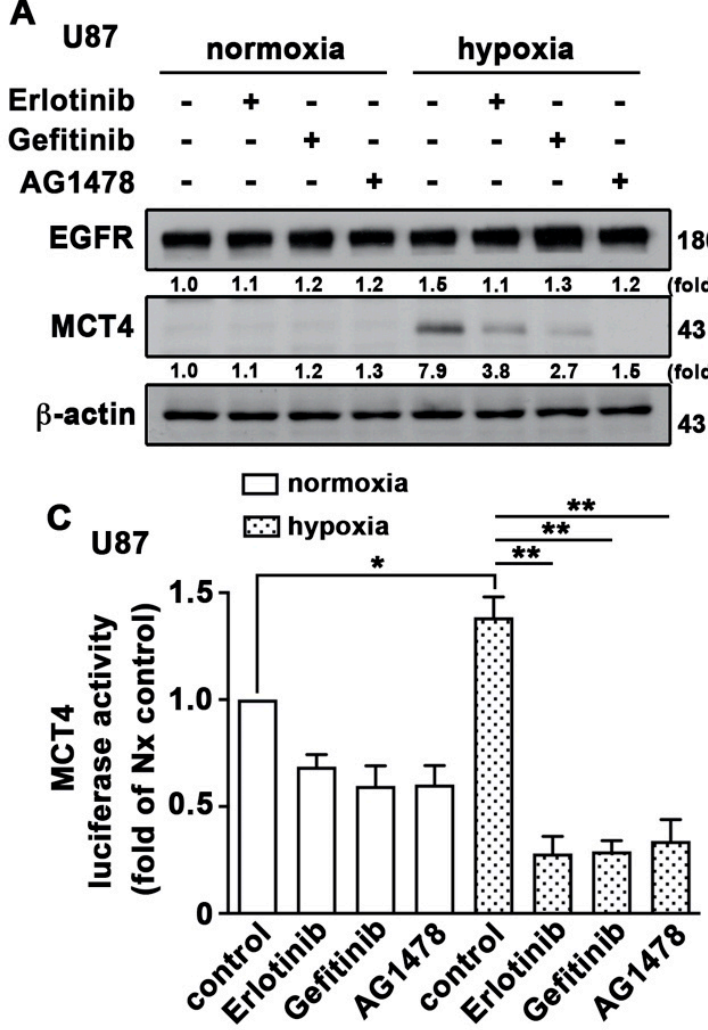

B

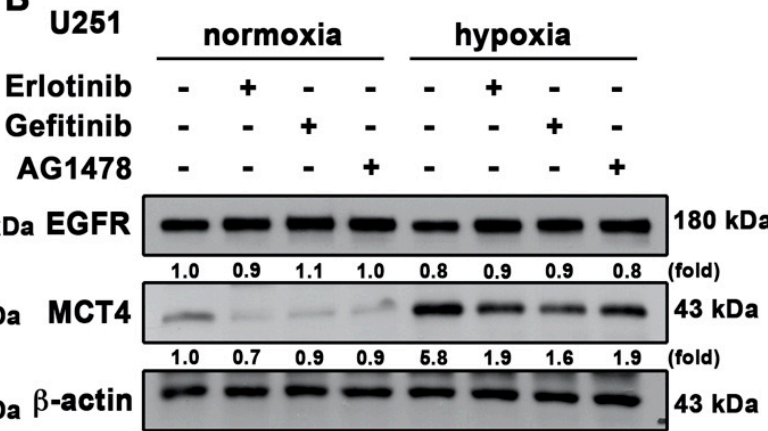

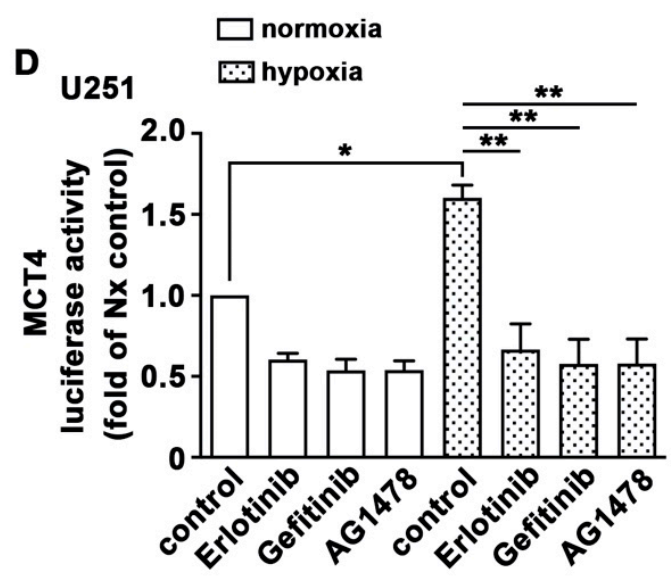

Figure 8. Activation of EGFR is involved in hypoxia-induced HIF-1 $\alpha$ and MCT4 expression in GBM. U87 (A) and U251 (B) cells were treated with EGFR inhibitors (50 nM erlotinib; $50 \mathrm{nM}$ gefitinib; $10 \mu \mathrm{M}$ AG1478) for $30 \mathrm{~min}$ and were exposed to hypoxic conditions $\left(1 \% \mathrm{O}_{2}\right)$ for another $24 \mathrm{~h}$. EGFR and MCT4 expression was determined using western blotting. U87 (C) and U251 (D) cells were transfected with MCT4 luciferase reporter plasmids for $24 \mathrm{~h}$ and were treated with EGFR inhibitors (50 $\mathrm{nM}$ erlotinib; $50 \mathrm{nM}$ gefitinib; $10 \mu \mathrm{M}$ AG1478) for $30 \mathrm{~min}$ and were then exposed to hypoxic conditions $\left(1 \% \mathrm{O}_{2}\right)$ for another $24 \mathrm{~h}$. Firefly luciferase activity was measured, and the results were normalized to renilla luciferase activity. Two-way ANOVA with a post-hoc Bonferroni test was used to examine the significance of the mean. ${ }^{*} p<0.05$ compared with normoxia control group. ${ }^{* *} p<0.01$ compared with the hypoxia-only group. Quantitative data are presented as the mean \pm S.E.M. $(n=3)$.

\subsection{Expression of MCT4 Is Elevated in the GBM Mouse Model}

Based on the strong correlation between MCT4 expression and poor outcomes in GBM, we further determined whether MCT4 was a modulator of aggressive cancer in an in vivo study. Mice were intracranially injected with mouse glioma ALTS1C1. Tumors were allowed to grow, and all animals were sacrificed 14 days after tumor implantation. Figure 9A shows the illustration of different brain regions we used in this study. Analysis of the tumor in the ALTS1C1-bearing mice showed that 
protein (Figure 9B,C) or gene (Figure 9D) expression levels of MCT4 were higher in tumor necrotic tissues compared with the adjacent tissues. Furthermore, MCT4 expression was further assessed by immunohistochemical staining and was found to be increased in the tumor necrotic areas of mice with GBM (Figure 9E). These results indicated that MCT4 levels were significantly correlated with the progression of GBM.

A
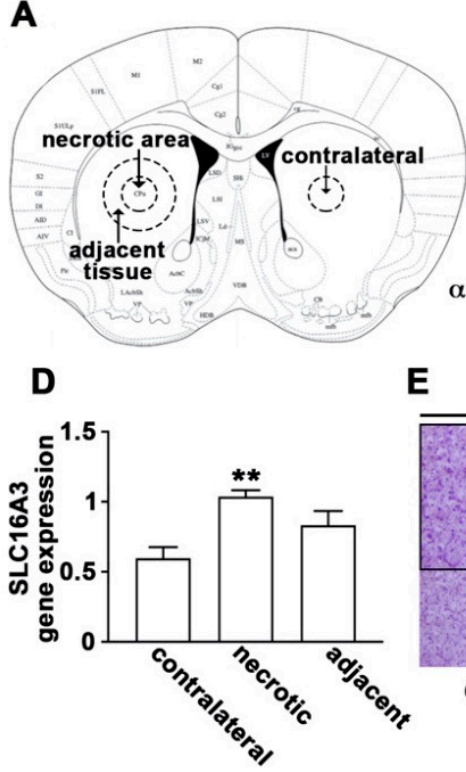

E

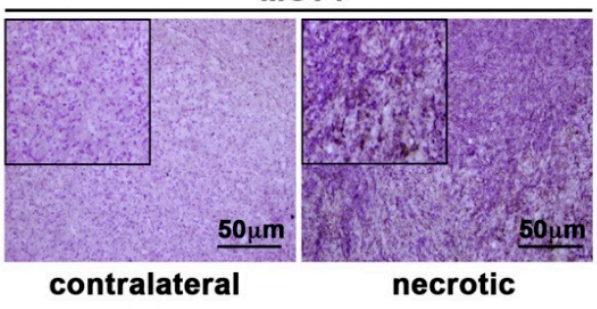

MCT4
C

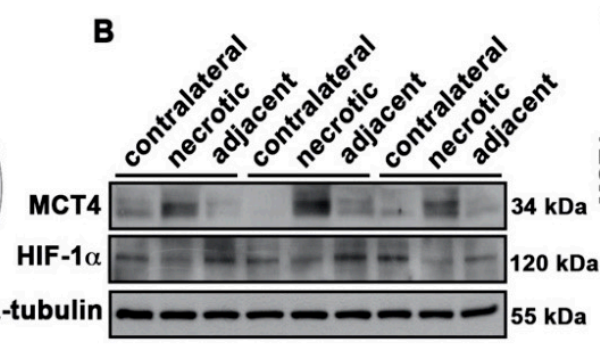

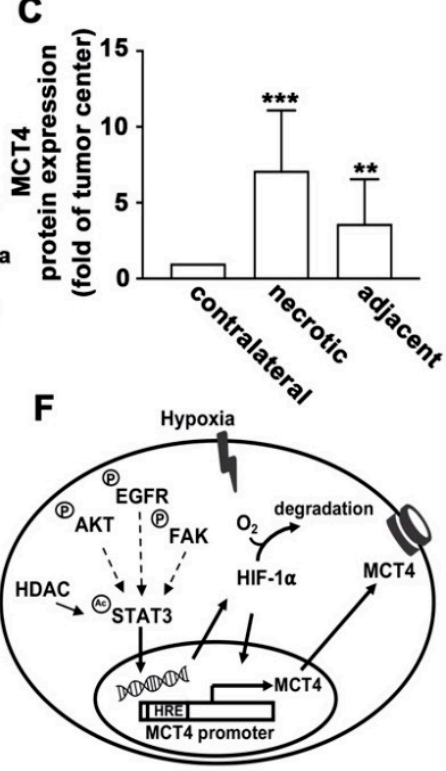

Figure 9. MCT4 expression is up-regulated in the GBM mouse model. ALTS1C1 (mouse GBM) cells were intracranially injected into the brain of C57BL/6 mice $(n=9)$. After 14 days, all the animals were sacrificed, and body weight was measured by using an electronic balance every other day until day 14. (A) The figure shows contralateral, necrotic, and adjacent tissues in the GBM mice model. MCT4 and HIF-1 $\alpha$ expression was determined using western blotting (B) and real-time PCR (D) in the GBM of ALTS1C1-bearing mice. (C) Quantification of MCT4 protein levels after western blotting analysis. One-way ANOVA with a post-hoc Bonferroni test was used to examine the significance of the mean. ** $p<0.01$ compared with the tumor contralateral group. ${ }^{* *} p<0.001$ compared with contralateral tumor group. Quantitative data are presented as the mean \pm S.E.M. $(n=3)$. (E) Immunohistochemistry with anti-MCT4 antibody in tumor tissue of GBM mice. (F) Schematic diagram showing the signaling pathways through which MCT4 modulates the microenvironment of GBM.

\section{Discussion}

Recent studies have focused on targeting the tumor microenvironment for anti-cancer therapies and for identifying a valuable biomarker for prognostic purposes. The present study demonstrated the differential expression of the lactate transporter MCT4 in GBM under hypoxia. DNA microarray (GEO dataset) analysis also indicated that the higher expression of MCT4 in patients with glioma correlated with a poor prognosis. Our finding also showed a positive correlation of MCT4 expression with GBM motility and monocyte adherent abilities of GBM. In addition, overexpression of MCT4 increased GBM motility and monocyte adhesion under normoxia conditions. Moreover, administration of the HIF- $1 \alpha$ inhibitor effectively reduced MCT4 expression. Furthermore, Pearson's correlation analysis showed a positive correlation between MCT4 and HIF- $1 \alpha$ expression levels in glioma patients. Using chromatin immunoprecipitation (ChIP) assays, we demonstrated that HIF- $1 \alpha$ binding to the hypoxia response element (HRE) binding site on the MCT4 promoter under hypoxia was regulated by acetylation of STAT3. Moreover, inhibition of STAT3 effectively reduced hypoxia-induced HIF- $1 \alpha$ and MCT4 expression. Finally, EGFR inhibitors erlotinib, gefitinib, and AG1478 effectively reduced the enhancement of HIF-1 $\alpha$ and MCT4 expression as well as MCT4 transcriptional activity under hypoxic 
conditions. Our study suggests that hypoxia-induced MCT4 expression enhances GBM progression by increasing GBM motility and monocyte recruitment (Figure 9F).

Lactic acidosis and hypoxia are two prominent microenvironmental stresses in solid tumors [52]. The present study suggests that MCT4 expression positively correlates with glioma grade and poor prognosis of patients with glioma (Figure 1D). Recently, increasing evidence has shown that lactate presence in the extracellular space, which is mediated by MCTs, has strong immunosuppressive effects [25]. In addition, MCT4 modulates macrophages into an M-2-like state that suppresses the inflammatory response and inhibits monocyte differentiation [53-55]. It has been demonstrated that classical MCT inhibitors and knockdown of MCT4 reduce the migration and invasion capacity of breast, lung, and glioma cells $[53,54,56,57]$. The present study also revealed that the overexpression of MCT4 was closely associated with monocyte adhesion (Figure 4A) and cell motility (Figure 4B). Our results showed that pharmacological (Figure 2A,B) or genetic (Figure 3A,B) inhibition of MCT4 significantly reduced monocyte adhesion ability. GBM exhibited increased expression levels of the MCT genes SLC16A1 and SLC16A3 when compared to normal brain parenchyma, as well as oligodendrogliomas and astrocytomas [39]. It has been reported that MCT4 is expressed in few cases of nonneoplastic brain tissues [58]. Brain samples from the GBM mouse model showed higher levels of MCT4 in tumor necrotic tissues compared to the adjacent tissues (Figure 9C,D). These findings suggest that MCT4 probably represents a critical therapeutic target for GBM and could serve as a prognostic indicator.

Post-translational modification is one of the mechanisms by which protein function is regulated by chronic hypoxia [59]. HIF-1 $\alpha$ is one of the most important regulators of dynamic balance between histone acetyl transferases (HATs) and histone deacetylases (HDACs) [60]. Hypoxia-mediated histone acetylation and expression of $\mathrm{N}$-myc transcription factor dominate aggressiveness of neuroblastoma cells [61]. Our results showed that HDAC inhibitors augmented hypoxia-induced HIF-1 $\alpha$ and MCT4 protein expression in the GBM cells (Figure 6C). In our previous study, STAT3 levels correlated significantly with the clinico-pathological grade of glioma. Moreover, STAT3 phosphorylation and translocation to the nucleus promote GBM migration [48]. Previous reports have indicated that STAT3 increases HIF- $1 \alpha$ protein stability and interacts with HIF- $1 \alpha$ target gene promoters [62]. Other reports have also shown that activation of STAT3 is involved in the modulation of expression of pH-regulating proteins, CA9 and MCT4 [63]. The present study revealed that acetyl-STAT3 was activated in response to hypoxia, and inhibition of STAT3 decreased hypoxia-induced MCT4 and HIF-1 $\alpha$ expression (Figure 6D,E). High levels of phosphorylated AKT have been reported to correlate with the poor prognosis of patients with GBM [64]. HIF- $1 \alpha$ has been shown to lie downstream of EGFR and AKT signaling and to activate VEGF expression in tumor cells [65]. In addition, our previous study also supports the finding that hypoxia-induced iNOS expression in microglia is HIF- $1 \alpha$-dependent and involves the activation of the PI3-kinase/AKT/mTOR signaling pathway [66]. Another study revealed that AKT inhibitors decrease HIF- $1 \alpha$ post-transcriptional protein levels, but not the transcriptional mRNA levels in the brain tissue [67]. However, FAK is typically considered as being upstream of AKT, and extracellular pressure stimulates cancer cell adhesion via AKT and FAK activation [47]. Over-activation of STAT3 is conducive to tumor invasiveness by up-regulation of FAK in gastric cancer cells [68]. Our present study found that FAK/STAT3 signaling is involved in GBM migration and IL-8 production [48]. In addition, numerous studies have suggested that EGFR is overexpressed in most primary GBM and is characteristic of more aggressive glioblastoma phenotypes [69,70]. Amplification of EGFR is associated with GBM proliferation and invasion [71]. Moreover, inhibition of GBM cells by EGFR is associated with anti-angiogenic and pro-apoptotic effects on the tumor [72]. It has been reported that coactivation of EGF and EGFR drives tumor metastasis via PI3K/AKT-dependent pathways [73]. Targeting FAK/STAT3 sensitizes gliomas to the anti-EGFR agent gefitinib and alkylating agent temozolomide in human gliomas [74]. Of note, small molecules against MCT4, as combination therapy with temozolomide, improve chemosensitivity and survival of GBM cells [58]. Our previous study has shown that STAT3 signaling is involved in the EGFR-associated adhesion molecule expression and monocyte adhesion in GBM [50]. Our results suggest that MCT4-regulated GBM motility and 
monocyte adhesion are mediated by activation of AKT, FAK, and EGFR signaling pathways. However, further research should explore the specific mechanism by which AKT, FAK, and EGFR/STAT3 affect the expression of MCT4 and should determine how $\mathrm{pH}$-regulating proteins affect GBM and form a suppressive immune microenvironment.

\section{Materials and Methods}

\subsection{Materials}

DMOG, AG1478 (EGFR inhibitor), SAHA (HDAC inhibitor), Trichostatin A (HDAC inhibitor), PF573228 (FAK inhibitor), and LY-294002 (PI3 kinase/AKT inhibitor) were obtained from Sigma-Aldrich (St. Louis, MO, USA). The HIF-1 inhibitor was obtained from Calbiochem (San Diego, CA, USA). Stattic (STAT3 inhibitor), erlotinib (EGFR inhibitor), and gefitinib (EGFR inhibitor) were obtained from Selleckchem (Houston, TX, USA). Primary antibodies against HIF-1 $\alpha$ (610958) were obtained from BD Biosciences (San Jose, CA, USA). Primary antibodies against GAPDH (SI-G8795) and $\alpha$-tubulin (SI-T5168) were obtained from Sigma-Aldrich. Primary antibodies against $\beta$-actin (sc-47778), PCNA (sc-56), AKT1 (sc-5298), p-AKT1/2/3 (sc-7985-R), FAK (sc-271195), and MCT4 (sc-376140) were obtained from Santa Cruz Biotechnology (Santa Cruz, CA, USA). Primary antibodies against Ac-STAT3 (2523), p-FAK (3283), and EGFR (4267) were obtained from Cell Signaling Technology (Danvers, MA, USA). On-Target smart pool MCT4 small interfering (si)RNA and control non-targeting siRNA were obtained from Dharmacon (Lafayette, CO, USA).

\subsection{Animals}

Male (8-week-old C57BL/6) mice were obtained from the National Laboratory Animal Center (Taipei, Taiwan) and were housed under standard laboratory conditions $\left(21 \pm 2{ }^{\circ} \mathrm{C}, 12 \mathrm{~h} \mathrm{~L} / \mathrm{D}\right.$ cycle, with food and water available ad libitum). All animal procedures were performed in accordance with the Animal Care and Use Guidelines of China Medical University (Taichung, Taiwan).

\subsection{Cell Culture}

Human glioma U251 cells were purchased from the Japanese Collection of Research Bioresources Cell Bank (JCRB NO. IFO50288, Japan). Human glioma U87 cells, mouse glioma ALTS1C1 cells, and human monocyte THP-1 were purchased from the Bioresource Collection and Research Center (BCRC No. 60360, 60582 and 60430; Taiwan). U251 and U87 cells were maintained with minimum essential medium (MEM), ALTS1C1 cells were maintained with Dulbecco's modified eagle medium (DMEM), and THP-1 cells were maintained with RPMI-1640 medium. All the culture cells were grown in medium containing 10\% fetal bovine serum (FBS), $100 \mathrm{mg} / \mathrm{mL}$ streptomycin, and $100 \mathrm{U} / \mathrm{mL}$ penicillin (PS). All the cells were incubated at $37^{\circ} \mathrm{C}$ in a humidified atmosphere containing $5 \% \mathrm{CO}_{2}$ and $95 \%$ air. For hypoxic exposure, cells were maintained at $37^{\circ} \mathrm{C}$ in a sealed acrylic chamber flushed with a gas mixture containing $1 \% \mathrm{O}_{2}, 5 \% \mathrm{CO}_{2}$, and $94 \% \mathrm{~N}_{2}$.

\subsection{Cytosolic and Nuclear Extracts}

Nuclear extracts were prepared as previously described [75]. Briefly, cells were rinsed with cold PBS and resuspended in a hypotonic buffer (10 mM HEPES, pH 7.6, $10 \mathrm{mM} \mathrm{KCl,1} \mathrm{mM} \mathrm{dithiothreitol,}$ $0.1 \mathrm{mM}$ EDTA, and protease inhibitor cocktail) for $10 \mathrm{~min}$ on ice. The cytosolic proteins were separated by centrifugation at $10,000 \times g$ for $2 \mathrm{~min}$. The supernatants containing the cytosolic proteins were collected, and the pellets containing the nuclear fraction were resuspended in buffer (20 mM HEPES pH 7.6, 1 mM EDTA, $1 \mathrm{mM}$ dithiothreitol, $0.4 \mathrm{M} \mathrm{NaCl}$, 25\% glycerol, and protease inhibitor cocktail) for $30 \mathrm{~min}$ on ice. The suspensions were centrifuged again at 13,000 $\mathrm{g}$ for $20 \mathrm{~min}$, and the supernatants containing the nuclear proteins were collected and stored at $-80{ }^{\circ} \mathrm{C}$. 


\subsection{Monocyte-Binding Assay}

The procedure of the monocyte-binding assay was described previously [76,77]. Briefly, human monocyte THP-1 cells were incubated with BCECF/AM (2',7'-bis-(2-carboxyethyl)-5-(and-6)carboxyfluorescein) and $0.1 \mu \mathrm{g}$ fluorescent dye of in RPMI-1640 medium in an incubator for $1 \mathrm{~h}$. GBM cells were treated with CHC or were transfected with short hairpin or wild-type MCT4 for the different time periods. Then, the medium was removed from the wells, and a monolayer of GBM cells was added with $2.0 \times 105$ BCECF/AM-labeled-THP-1 cells to each well. Non-adherent monocytes were removed and gently washed twice with culture medium and incubated for $45 \mathrm{~min}$. The adherent monocytes were then photographed and counted using a fluorescence microscope.

\subsection{Western Blotting}

Western blotting of whole cell extracts was performed according to a previous study [78]. Briefly, cells were extracted with RIPA lysis buffer; the cells were collected by a scraper and were kept on ice. The protein samples were spun at 13,000× rpm for $20 \mathrm{~min}$, after which the supernatant was collected and stored at $-20^{\circ} \mathrm{C}$. Protein samples were separated by sodium dodecyl sulfate-polyacrylamide gel electrophoresis and were then transferred onto PVDF membranes (Millipore, Bedford, MA, USA). Membranes were blocked by non-fat dry milk (5\%) in TBST for $1 \mathrm{~h}$. The membranes were incubated with primary antibodies at $4{ }^{\circ} \mathrm{C}$ overnight or with RT for $1 \mathrm{~h}$. Following washes with TBST buffer, the membranes were incubated with anti-mouse or anti-rabbit HRP-conjugates secondary antibodies. Protein bands were visualized by ECL and Kodak X-OMAT LS film (Eastman Kodak, Rochester, NY, USA). The data were quantified using ImageJ software (National Institutes of Health, Bethesda, Maryland, USA, https://imagej.nih.gov/ij/, 1997-2018).

\subsection{Reverse Transcription and Real-Time PCR}

Total RNA was isolated from GBM cells by TRIzol (TRI Reagent), and the concentration of RNA was measured with a BioDrop spectrophotometer. The target gene expression was detected by quantitative real-time PCR (q-PCR). The messenger RNA converted into cDNA by reverse transcription (RT) using an Invitrogen Reverse Transcription Kit and was amplified using the oligonucleotide primers as follows: hHIF-1 $\alpha$ : 5' -TTACA GCAGC CAGAC GATCA-3' and 5'-CCCTG CAGTA GGTTT CTGCT- $3^{\prime}$; hMCT4: 5'-GAGTT TGGGA TCGGC TACAG-3' and 5'-CGGTT CACGC ACACA CTG-3', and internal control h36B4: 5'-AGATG CAGCA GATCC GCAT-3' and 5'-GTTCT TGCCC ATCAG CACC-3'. The PCR reaction using SYBR Green Master Mix (Applied Biosystems, Foster City, CA, USA) was performed on a StepOne Plus Real-Time PCR System. The threshold was set within the linear phase of target gene amplification to calculate the cycle number at which the transcript was detected (denoted as CT).

\subsection{Luciferase Reporter Assay}

GBM cells were transfected with MCT4 firefly luciferase reporter plasmids and SV40-renilla luciferase control plasmids using Lipofectamine 3000 (Invitrogen) according to the manufacturer's recommendations. After $24 \mathrm{~h}$ transfection, the cells were pretreated with inhibitors for $40 \mathrm{~min}$ and were then exposed to hypoxia for $24 \mathrm{~h}$. Cell extracts were then prepared, and firefly and renilla luciferase activities were measured.

\subsection{Cell Transfection}

GBM cells were transiently transfected with wild-type MCT4 and MCT4 luciferase reporter plasmids using Lipofectamine (LF)3000 (Invitrogen) for $24 \mathrm{~h}$. Plasmid DNA and LF3000 were premixed in serum-free medium for $5 \mathrm{~min}$ and were then applied to the cells. The LF3000-containing medium was replaced with fresh serum-free medium after $24 \mathrm{~h}$. GBM cells were transiently transfected with shRNA against MCT4 or control shRNA (Dharmacon, Lafayette, CO, USA) using DharmaFECT 
transfection reagents (Dharmacon). The shRNA or the negative control were premixed with the DharmaFECT transfection reagent in a serum-free medium for $10 \mathrm{~min}$ and were then used to transfect the cells. After $24 \mathrm{~h}$ incubation, the medium containing Lipofectamine 3000 was replaced with fresh serum-free medium.

\subsection{Cell Migration Assay}

In vitro migration assay was performed using a Costar transwell insert (8- $\mu \mathrm{m}$ pore size; Costar, NY, USA) in 24-well plates as previously described [48]. Prior to the migration assay, the GBM cells were treated with $\mathrm{CHC}$ or were transfected with short hairpin or wild-type MCT4. Approximately $2 \times 10^{4}$ GBM cells in $200 \mu \mathrm{L}$ of serum-free medium were placed in the upper chamber, and $400 \mu \mathrm{L}$ of the same medium was placed in the lower chamber. The plates were incubated for $24 \mathrm{~h}$ at $37^{\circ} \mathrm{C}$ under hypoxic conditions $\left(1 \% \mathrm{O}_{2}\right)$. The cells that migrated through the filters were fixed with $3.7 \%$ formaldehyde for $5 \mathrm{~min}$ and then stained with $0.05 \%$ crystal violet for $30 \mathrm{~min}$. Cells on the upper side of the filters were wiped with cotton-tipped swabs, and the cells on the underside of the filter were photographed using a digital camera mounted on a microscope.

\subsection{Chromatin Immunoprecipitation (ChIP) Assay}

The ChIP assay was performed using an EZ-Magna ChIPTM A/G Chromatin Immunoprecipitation Kit (Millipore, Billerica, MA, USA) as previously described [50] using isolated nuclei from the formaldehyde cross-linked GBM cells. Immunoprecipitation was performed using the primary antibodies against HIF-1 $\alpha$ and magnetic beads. Normal mouse IgG was used as a negative control, and $1 \mu \mathrm{g}$ of antibody was used for each reaction. The diluted chromatin was then incubated on a rotator at $4{ }^{\circ} \mathrm{C}$ for overnight and then extracted and purified. Purified DNA was subjected to PCR amplification using the oligonucleotide primers, 5' -AACGC TCTGG TTGCA AATAA AA-3' and 5'-ACGCA CTTGT AATTA CTCAA ACA-3', which were used to amplify the MCT4 promoter region. The PCR products were resolved by $2 \%$ agarose gel electrophoresis and were visualized under UV light.

\subsection{GEO Gene Expression Database}

The DNA microarray data were obtained from the glioma patient dataset, accession number GSE4290. The expression levels of target genes were analyzing using GraphPad Prism 6 software from the publicly available Gene Expression Omnibus (GEO) databases. The glioma patients were collected from the Henry Ford Hospital (HFH) that contains 180 glioma patients with histologically confirmed different grades of glioma: grade IV astrocytomas (GBM $n=81$ ), grade III (astrocytomas $n=19$, oligodendrogliomas $n=12$ ), grade II (astrocytomas $n=7$, oligodendrogliomas $n=38$ ), and non-tumors $n=23$. The gene expression of HIF-1 $\alpha$ and MCT4 was obtained from the GSE4290 dataset and correlated with the human glioma pathological grade.

\subsection{Intracranial Tumor Implantation}

ALTS1C1 was freshly prepared and adjusted to $1 \times 10^{5}$ cells/mL before implantation. An intracranial injection was performed according to protocols approved by the China Medical University Animal Care and Use Committee. Briefly, C57BL/6 mice were anesthetized and placed in a stereotactic frame, and the skulls were exposed by incision. In each skull, a hole was made, $0.8 \mathrm{~mm}$ anterior, $2.5 \mathrm{~mm}$ to the right of the bregma, and cells $(2 \mu \mathrm{L})$ were injected using a 10- $\mu \mathrm{L}$ Hamilton syringe with a 26S-gage needle mounted in a stereotactic holder. The syringe was lowered to a depth of $3 \mathrm{~mm}$, and the cells were injected at a rate of $0.4 \mu \mathrm{L} / \mathrm{min}$. After intracranial implantation, a 5-min waiting period was observed before slowly withdrawing the syringe to prevent any reflux. The skull was then cleaned, and the incision was sutured. Tumors were allowed to grow, and all animals were sacrificed 24 days after tumor implantation. 


\subsection{Immunohistochemistry}

The protocol for immunohistochemistry was performed as described in our previous report [79]. Briefly, brain tumor tissues on glass slides were rehydrated and quenched for endogenous peroxidases with hydrogen peroxide. After being deparaffinized, the sections were blocked by incubation in PBS containing 3\% bovine serum albumin. The anti-MCT4 primary antibody was applied to the slides at a dilution of 1:50, followed by overnight incubation at $4{ }^{\circ} \mathrm{C}$. After several washes with PBS, the samples were incubated with the biotin-conjugated secondary antibody at dilution of 1:50. Bound antibodies were detected with the ABC reaction kit (Vector Laboratories; Burlington, CA, USA), developed with diaminobenzene (Sigma-Aldrich), and counterstained with hematoxylin. The results were presented the mean \pm S.E.M. and all the data were collected using at least three biologically independent replicates.

\subsection{Statistics}

The results are presented as the mean \pm S.E.M., and all the data were collected based on at least three biologically independent replicates. The values were determined using ImageJ software and GraphPad Prism 8 software (version 8, GraphPad software Inc., San Diego, CA, USA). The data given are based on statistical analysis between two samples that was performed using a Student's $t$-test. For multiple comparisons, one-way ANOVA or two-way ANOVA was performed, followed by the Bonferroni test. In all cases, a $p$-value $<0.05$ was considered to be statistically significance. The $p$-values are indicated in the figure legends. No pre-test was used to choose the sample size.

\section{Conclusions}

In this study, we elucidated the mechanism by which EGFR and acetylated STAT3 stabilize HIF- $1 \alpha$ and further regulate the expression of MCT4 and thus affect GBM motility and monocyte adhesion under hypoxia. In vivo studies suggested that MCT4 was up-regulated in the GBM mouse model. Of note, the MCT4 level was significantly increased in the tumor necrotic tissues of GBM. These findings raise the possibility that strategies targeting MCT4 might provide an opportunity for the development of novel therapeutic targets.

Supplementary Materials: The following are available online at http://www.mdpi.com/2072-6694/12/2/380/s1, Figure S1: Effects of MCT4 knockdown on hypoxia-induced extracellular acidosis. Figure S2: Protein expression under overexpression of MCT4 in GBM.

Author Contributions: S.-W.L. and D.-Y.L. conceived, designed the studies, and wrote the paper; S.-W.L. and H.-J.L. created the plasmid constructs; S.-W.L. and H.-J.L. performed the experiments; S.-W.L., L.-Y.Y., and D.-Y.L. discussed the studies; S.-W.L. and Y.-S.L. performed the statistical analysis. All authors have read and agreed to the published version of the manuscript.

Funding: This work was supported in part by grants from the Ministry of Science and Technology, Taiwan (105-2320-B-468-004-MY3, 108-2320-B-039-015 and 109-2622-8-039-002 -TB1) and China Medical University, Taiwan (CMU105-ASIA-21 and CMU 107-ASIA-16).

Conflicts of Interest: The authors declare no biomedical financial interest or potential conflict of interest.

\section{References}

1. Huse, J.T.; Holland, E.C. Targeting brain cancer: Advances in the molecular pathology of malignant glioma and medulloblastoma. Nat. Rev. Cancer 2010, 10, 319-331. [CrossRef] [PubMed]

2. Thakkar, J.P.; Dolecek, T.A.; Horbinski, C.; Ostrom, Q.T.; Lightner, D.D.; Barnholtz-Sloan, J.S.; Villano, J.L. Epidemiologic and molecular prognostic review of glioblastoma. Cancer Epidemiol. Biomark. Prev. 2014, 23, 1985-1996. [CrossRef] [PubMed]

3. Angelin, A.; Gil-de-Gomez, L.; Dahiya, S.; Jiao, J.; Guo, L.; Levine, M.H.; Wang, Z.; Quinn, W.J., 3rd; Kopinski, P.K.; Wang, L.; et al. Foxp3 Reprograms T Cell Metabolism to Function in Low-Glucose, High-Lactate Environments. Cell Metab. 2017, 25, 1282-1293. [CrossRef] [PubMed] 
4. Zinnhardt, B.; Pigeon, H.; Theze, B.; Viel, T.; Wachsmuth, L.; Fricke, I.B.; Schelhaas, S.; Honold, L.; Schwegmann, K.; Wagner, S.; et al. Combined PET Imaging of the Inflammatory Tumor Microenvironment Identifies Margins of Unique Radiotracer Uptake. Cancer Res. 2017, 77, 1831-1841. [CrossRef]

5. Brat, D.J.; Van Meir, E.G. Vaso-occlusive and prothrombotic mechanisms associated with tumor hypoxia, necrosis, and accelerated growth in glioblastoma. Lab. Investig. 2004, 84, 397-405. [CrossRef]

6. Monteiro, A.R.; Hill, R.; Pilkington, G.J.; Madureira, P.A. The Role of Hypoxia in Glioblastoma Invasion. Cells 2017, 6, 45. [CrossRef]

7. Dubois, L.G.; Campanati, L.; Righy, C.; D’Andrea-Meira, I.; Spohr, T.C.; Porto-Carreiro, I.; Pereira, C.M.; Balca-Silva, J.; Kahn, S.A.; DosSantos, M.F.; et al. Gliomas and the vascular fragility of the blood brain barrier. Front. Cell Neurosci. 2014, 8, 418. [CrossRef]

8. Parks, S.K.; Chiche, J.; Pouyssegur, J. Disrupting proton dynamics and energy metabolism for cancer therapy. Nat. Rev. Cancer 2013, 13, 611-623. [CrossRef]

9. Martinez, D.; Vermeulen, M.; Trevani, A.; Ceballos, A.; Sabatte, J.; Gamberale, R.; Alvarez, M.E.; Salamone, G.; Tanos, T.; Coso, O.A.; et al. Extracellular acidosis induces neutrophil activation by a mechanism dependent on activation of phosphatidylinositol 3-kinase/Akt and ERK pathways. J. Immunol. 2006, 176, 1163-1171. [CrossRef]

10. Jancic, C.C.; Cabrini, M.; Gabelloni, M.L.; Rodriguez Rodrigues, C.; Salamone, G.; Trevani, A.S.; Geffner, J. Low extracellular $\mathrm{pH}$ stimulates the production of IL-1beta by human monocytes. Cytokine 2012, 57, $258-268$. [CrossRef]

11. Zagzag, D.; Lukyanov, Y.; Lan, L.; Ali, M.A.; Esencay, M.; Mendez, O.; Yee, H.; Voura, E.B.; Newcomb, E.W. Hypoxia-inducible factor 1 and VEGF upregulate CXCR4 in glioblastoma: Implications for angiogenesis and glioma cell invasion. Lab. Investig. 2006, 86, 1221-1232. [CrossRef]

12. Masson, N.; Ratcliffe, P.J. Hypoxia signaling pathways in cancer metabolism: The importance of co-selecting interconnected physiological pathways. Cancer Metab. 2014, 2, 3. [CrossRef]

13. Hockel, M.; Vaupel, P. Tumor hypoxia: Definitions and current clinical, biologic, and molecular aspects. J. Natl. Cancer Inst. 2001, 93, 266-276. [CrossRef]

14. Masoud, G.N.; Li, W. HIF-1alpha pathway: Role, regulation and intervention for cancer therapy. Acta Pharm. Sin. B 2015, 5, 378-389. [CrossRef]

15. Semenza, G.L. HIF-1 mediates metabolic responses to intratumoral hypoxia and oncogenic mutations. J. Clin. Investig. 2013, 123, 3664-3671. [CrossRef]

16. Qiang, L.; Wu, T.; Zhang, H.W.; Lu, N.; Hu, R.; Wang, Y.J.; Zhao, L.; Chen, F.H.; Wang, X.T.; You, Q.D.; et al. HIF-1alpha is critical for hypoxia-mediated maintenance of glioblastoma stem cells by activating Notch signaling pathway. Cell Death Differ. 2012, 19, 284-294. [CrossRef]

17. Lo Dico, A.; Martelli, C.; Diceglie, C.; Lucignani, G.; Ottobrini, L. Hypoxia-Inducible Factor-1alpha Activity as a Switch for Glioblastoma Responsiveness to Temozolomide. Front. Oncol. 2018, 8, 249. [CrossRef]

18. Shen, S.H.; Kwan, A.L.; Chen, Y.Y.; Wang, Z.X. Effect of silencing HIF-1alpha on proliferation, invasion and migration of glioblastoma U87 cells. Neurol. Sci. 2013, 34, 365-371. [CrossRef]

19. Luo, Z.; Bai, M.; Xiao, X.; Zhang, W.; Liu, X.; Yang, X.; Li, S.; Huan, Y.; Wu, Z.; Zhang, X.; et al. Silencing of HIF-1alpha enhances the radiation sensitivity of human glioma growth in vitro and in vivo. Neuropharmacology 2015, 89, 168-174. [CrossRef]

20. Oliver, L.; Olivier, C.; Marhuenda, F.B.; Campone, M.; Vallette, F.M. Hypoxia and the malignant glioma microenvironment: Regulation and implications for therapy. Curr. Mol. Pharmacol. 2009, 2, 263-284. [CrossRef]

21. Reszec, J.; Hermanowicz, A.; Rutkowski, R.; Bernaczyk, P.; Mariak, Z.; Chyczewski, L. Evaluation of mast cells and hypoxia inducible factor-1 expression in meningiomas of various grades in correlation with peritumoral brain edema. J. Neurooncol. 2013, 115, 119-125. [CrossRef]

22. Vander Heiden, M.G.; Cantley, L.C.; Thompson, C.B. Understanding the Warburg effect: The metabolic requirements of cell proliferation. Science 2009, 324, 1029-1033. [CrossRef]

23. Schulze, A.; Harris, A.L. How cancer metabolism is tuned for proliferation and vulnerable to disruption. Nature 2012, 491, 364-373. [CrossRef]

24. Li, Y.; Patel, S.P.; Roszik, J.; Qin, Y. Hypoxia-Driven Immunosuppressive Metabolites in the Tumor Microenvironment: New Approaches for Combinational Immunotherapy. Front. Immunol. 2018, 9, 1591. [CrossRef] 
25. Husain, Z.; Huang, Y.; Seth, P.; Sukhatme, V.P. Tumor-derived lactate modifies antitumor immune response: Effect on myeloid-derived suppressor cells and NK cells. J. Immunol. 2013, 191, 1486-1495. [CrossRef]

26. Helmlinger, G.; Yuan, F.; Dellian, M.; Jain, R.K. Interstitial $\mathrm{pH}$ and $\mathrm{pO}_{2}$ gradients in solid tumors in vivo: High-resolution measurements reveal a lack of correlation. Nat. Med. 1997, 3, 177-182. [CrossRef]

27. Halestrap, A.P. Monocarboxylic acid transport. Compr. Physiol. 2013, 3, 1611-1643. [CrossRef]

28. Chiche, J.; Le Fur, Y.; Vilmen, C.; Frassineti, F.; Daniel, L.; Halestrap, A.P.; Cozzone, P.J.; Pouyssegur, J.; Lutz, N.W. In vivo $\mathrm{pH}$ in metabolic-defective Ras-transformed fibroblast tumors: Key role of the monocarboxylate transporter, MCT4, for inducing an alkaline intracellular pH. Int. J. Cancer 2012, 130, 1511-1520. [CrossRef]

29. Enerson, B.E.; Drewes, L.R. Molecular features, regulation, and function of monocarboxylate transporters: Implications for drug delivery. J. Pharm. Sci. 2003, 92, 1531-1544. [CrossRef]

30. Vegran, F.; Boidot, R.; Michiels, C.; Sonveaux, P.; Feron, O. Lactate influx through the endothelial cell monocarboxylate transporter MCT1 supports an NF-kappaB/IL-8 pathway that drives tumor angiogenesis. Cancer Res. 2011, 71, 2550-2560. [CrossRef]

31. Halestrap, A.P. The SLC16 gene family-structure, role and regulation in health and disease. Mol. Asp. Med. 2013, 34, 337-349. [CrossRef]

32. Izumi, H.; Torigoe, T.; Ishiguchi, H.; Uramoto, H.; Yoshida, Y.; Tanabe, M.; Ise, T.; Murakami, T.; Yoshida, T.; Nomoto, M.; et al. Cellular $\mathrm{pH}$ regulators: Potentially promising molecular targets for cancer chemotherapy. Cancer Treat. Rev. 2003, 29, 541-549. [CrossRef]

33. Simoes-Sousa, S.; Granja, S.; Pinheiro, C.; Fernandes, D.; Longatto-Filho, A.; Laus, A.C.; Alves, C.D.; Suarez-Penaranda, J.M.; Perez-Sayans, M.; Lopes Carvalho, A.; et al. Prognostic significance of monocarboxylate transporter expression in oral cavity tumors. Cell Cycle 2016, 15, 1865-1873. [CrossRef]

34. Sonveaux, P.; Vegran, F.; Schroeder, T.; Wergin, M.C.; Verrax, J.; Rabbani, Z.N.; De Saedeleer, C.J.; Kennedy, K.M.; Diepart, C.; Jordan, B.F.; et al. Targeting lactate-fueled respiration selectively kills hypoxic tumor cells in mice. J. Clin. Investig. 2008, 118, 3930-3942. [CrossRef]

35. Pistollato, F.; Chen, H.L.; Schwartz, P.H.; Basso, G.; Panchision, D.M. Oxygen tension controls the expansion of human CNS precursors and the generation of astrocytes and oligodendrocytes. Mol. Cell Neurosci. 2007, 35, 424-435. [CrossRef]

36. Ullah, M.S.; Davies, A.J.; Halestrap, A.P. The plasma membrane lactate transporter MCT4, but not MCT1, is up-regulated by hypoxia through a HIF-1alpha-dependent mechanism. J. Biol. Chem. 2006, 281, 9030-9037. [CrossRef]

37. Le Floch, R.; Chiche, J.; Marchiq, I.; Naiken, T.; Ilc, K.; Murray, C.M.; Critchlow, S.E.; Roux, D.; Simon, M.P.; Pouyssegur, J. CD147 subunit of lactate/H+ symporters MCT1 and hypoxia-inducible MCT4 is critical for energetics and growth of glycolytic tumors. Proc. Natl. Acad. Sci. USA 2011, 108, 16663-16668. [CrossRef]

38. Spina, R.; Voss, D.M.; Asnaghi, L.; Sloan, A.; Bar, E.E. Flow Cytometry-based Drug Screening System for the Identification of Small Molecules That Promote Cellular Differentiation of Glioblastoma Stem Cells. J. Vis. Exp. 2018, 131, e56176. [CrossRef]

39. Park, S.J.; Smith, C.P.; Wilbur, R.R.; Cain, C.P.; Kallu, S.R.; Valasapalli, S.; Sahoo, A.; Guda, M.R.; Tsung, A.J.; Velpula, K.K. An overview of MCT1 and MCT4 in GBM: Small molecule transporters with large implications. Am. J. Cancer Res. 2018, 8, 1967-1976.

40. Pinheiro, C.; Longatto-Filho, A.; Azevedo-Silva, J.; Casal, M.; Schmitt, F.C.; Baltazar, F. Role of monocarboxylate transporters in human cancers: State of the art. J. Bioenerg. Biomembr. 2012, 44, 127-139. [CrossRef]

41. Lim, K.S.; Lim, K.J.; Price, A.C.; Orr, B.A.; Eberhart, C.G.; Bar, E.E. Inhibition of monocarboxylate transporter-4 depletes stem-like glioblastoma cells and inhibits HIF transcriptional response in a lactate-independent manner. Oncogene 2014, 33, 4433-4441. [CrossRef]

42. Tan, Z.; Xie, N.; Banerjee, S.; Cui, H.; Fu, M.; Thannickal, V.J.; Liu, G. The monocarboxylate transporter 4 is required for glycolytic reprogramming and inflammatory response in macrophages. J. Biol. Chem. 2015, 290, 46-55. [CrossRef]

43. Ke, Q.; Costa, M. Hypoxia-inducible factor-1 (HIF-1). Mol. Pharmacol. 2006, 70, 1469-1480. [CrossRef]

44. Bar, E.E. Glioblastoma, cancer stem cells and hypoxia. Brain Pathol. 2011, 21, 119-129. [CrossRef]

45. Yang, X.J.; Seto, E. Collaborative spirit of histone deacetylases in regulating chromatin structure and gene expression. Curr. Opin. Genet. Dev. 2003, 13, 143-153. [CrossRef] 
46. Yang, X.J.; Gregoire, S. Class II histone deacetylases: From sequence to function, regulation, and clinical implication. Mol. Cell Biol. 2005, 25, 2873-2884. [CrossRef]

47. Wang, S.; Basson, M.D. Akt directly regulates focal adhesion kinase through association and serine phosphorylation: Implication for pressure-induced colon cancer metastasis. Am. J. Physiol. Cell Physiol. 2011, 300, C657-C670. [CrossRef]

48. Liu, Y.S.; Hsu, J.W.; Lin, H.Y.; Lai, S.W.; Huang, B.R.; Tsai, C.F.; Lu, D.Y. Bradykinin B1 receptor contributes to interleukin-8 production and glioblastoma migration through interaction of STAT3 and SP-1. Neuropharmacology 2019, 144, 143-154. [CrossRef]

49. Lee, S.H.; Lee, Y.J.; Song, C.H.; Ahn, Y.K.; Han, H.J. Role of FAK phosphorylation in hypoxia-induced hMSCS migration: Involvement of VEGF as well as MAPKS and eNOS pathways. Am. J. Physiol. Cell Physiol. 2010, 298, C847-C856. [CrossRef]

50. Liu, Y.S.; Lin, H.Y.; Lai, S.W.; Huang, C.Y.; Huang, B.R.; Chen, P.Y.; Wei, K.C.; Lu, D.Y. MiR-181b modulates EGFR-dependent VCAM-1 expression and monocyte adhesion in glioblastoma. Oncogene 2017, 36, 5006-5022. [CrossRef]

51. Ruano, Y.; Ribalta, T.; de Lope, A.R.; Campos-Martin, Y.; Fiano, C.; Perez-Magan, E.; Hernandez-Moneo, J.L.; Mollejo, M.; Melendez, B. Worse outcome in primary glioblastoma multiforme with concurrent epidermal growth factor receptor and p53 alteration. Am. J. Clin. Pathol. 2009, 131, 257-263. [CrossRef] [PubMed]

52. Tang, X.; Lucas, J.E.; Chen, J.L.; LaMonte, G.; Wu, J.; Wang, M.C.; Koumenis, C.; Chi, J.T. Functional interaction between responses to lactic acidosis and hypoxia regulates genomic transcriptional outputs. Cancer Res. 2012, 72, 491-502. [CrossRef]

53. Izumi, H.; Takahashi, M.; Uramoto, H.; Nakayama, Y.; Oyama, T.; Wang, K.Y.; Sasaguri, Y.; Nishizawa, S.; Kohno, K. Monocarboxylate transporters 1 and 4 are involved in the invasion activity of human lung cancer cells. Cancer Sci. 2011, 102, 1007-1013. [CrossRef]

54. Gallagher, S.M.; Castorino, J.J.; Wang, D.; Philp, N.J. Monocarboxylate transporter 4 regulates maturation and trafficking of CD147 to the plasma membrane in the metastatic breast cancer cell line MDA-MB-231. Cancer Res. 2007, 67, 4182-4189. [CrossRef]

55. McDonald, P.C.; Chafe, S.C.; Dedhar, S. Overcoming Hypoxia-Mediated Tumor Progression: Combinatorial Approaches Targeting pH Regulation, Angiogenesis and Immune Dysfunction. Front. Cell Dev. Biol. 2016, 4, 27. [CrossRef]

56. Zhu, J.; Wu, Y.N.; Zhang, W.; Zhang, X.M.; Ding, X.; Li, H.Q.; Geng, M.; Xie, Z.Q.; Wu, H.M. Monocarboxylate transporter 4 facilitates cell proliferation and migration and is associated with poor prognosis in oral squamous cell carcinoma patients. PLoS ONE 2014, 9, e87904. [CrossRef]

57. Colen, C.B.; Shen, Y.; Ghoddoussi, F.; Yu, P.; Francis, T.B.; Koch, B.J.; Monterey, M.D.; Galloway, M.P.; Sloan, A.E.; Mathupala, S.P. Metabolic targeting of lactate efflux by malignant glioma inhibits invasiveness and induces necrosis: An in vivo study. Neoplasia 2011, 13, 620-632. [CrossRef]

58. Miranda-Goncalves, V.; Honavar, M.; Pinheiro, C.; Martinho, O.; Pires, M.M.; Pinheiro, C.; Cordeiro, M.; Bebiano, G.; Costa, P.; Palmeirim, I.; et al. Monocarboxylate transporters (MCTs) in gliomas: Expression and exploitation as therapeutic targets. Neuro Oncol. 2013, 15, 172-188. [CrossRef]

59. Kumar, G.K.; Prabhakar, N.R. Post-translational modification of proteins during intermittent hypoxia. Respir. Physiol. Neurobiol. 2008, 164, 272-276. [CrossRef]

60. Liang, D.; Kong, X.; Sang, N. Effects of histone deacetylase inhibitors on HIF-1. Cell Cycle 2006, 5, $2430-2435$. [CrossRef]

61. Poljakova, J.; Groh, T.; Gudino, Z.O.; Hrabeta, J.; Borek-Dohalska, L.; Kizek, R.; Doktorova, H.; Eckschlager, T.; Stiborova, M. Hypoxia-mediated histone acetylation and expression of $\mathrm{N}$-myc transcription factor dictate aggressiveness of neuroblastoma cells. Oncol. Rep. 2014, 31, 1928-1934. [CrossRef] [PubMed]

62. Cui, Y.; Li, Y.Y.; Li, J.; Zhang, H.Y.; Wang, F.; Bai, X.; Li, S.S. STAT3 regulates hypoxia-induced epithelial mesenchymal transition in oesophageal squamous cell cancer. Oncol. Rep. 2016, 36, 108-116. [CrossRef] [PubMed]

63. Silva, L.S.; Goncalves, L.G.; Silva, F.; Domingues, G.; Maximo, V.; Ferreira, J.; Lam, E.W.; Dias, S.; Felix, A.; Serpa, J. STAT3:FOXM1 and MCT1 drive uterine cervix carcinoma fitness to a lactate-rich microenvironment. Tumour Biol. 2016, 37, 5385-5395. [CrossRef] [PubMed] 
64. Suzuki, Y.; Shirai, K.; Oka, K.; Mobaraki, A.; Yoshida, Y.; Noda, S.E.; Okamoto, M.; Suzuki, Y.; Itoh, J.; Itoh, H.; et al. Higher pAkt expression predicts a significant worse prognosis in glioblastomas. J. Radiat. Res. 2010, 51, 343-348. [CrossRef]

65. Liu, Y.S.; Huang, Z.W.; Qin, A.Q.; Huang, Y.; Giordano, F.; Lu, Q.H.; Jiang, W.D. The expression of epidermal growth factor-like domain 7 regulated by oxygen tension via hypoxia inducible factor (HIF)-1alpha activity. Postgrad. Med. 2015, 127, 144-149. [CrossRef]

66. Lu, D.Y.; Liou, H.C.; Tang, C.H.; Fu, W.M. Hypoxia-induced iNOS expression in microglia is regulated by the PI3-kinase/Akt/mTOR signaling pathway and activation of hypoxia inducible factor-1alpha. Biochem. Pharmacol. 2006, 72, 992-1000. [CrossRef]

67. Li, L.; Qu, Y.; Mao, M.; Xiong, Y.; Mu, D. The involvement of phosphoinositid 3-kinase/Akt pathway in the activation of hypoxia-inducible factor-1alpha in the developing rat brain after hypoxia-ischemia. Brain Res. 2008, 1197, 152-158. [CrossRef]

68. Wei, Z.; Jiang, X.; Qiao, H.; Zhai, B.; Zhang, L.; Zhang, Q.; Wu, Y.; Jiang, H.; Sun, X. STAT3 interacts with Skp2/p27/p21 pathway to regulate the motility and invasion of gastric cancer cells. Cell Signal 2013, 25, 931-938. [CrossRef]

69. Verhaak, R.G.; Hoadley, K.A.; Purdom, E.; Wang, V.; Qi, Y.; Wilkerson, M.D.; Miller, C.R.; Ding, L.; Golub, T.; Mesirov, J.P.; et al. Integrated genomic analysis identifies clinically relevant subtypes of glioblastoma characterized by abnormalities in PDGFRA, IDH1, EGFR, and NF1. Cancer Cell 2010, 17, 98-110. [CrossRef]

70. Alvarez, J.V.; Mukherjee, N.; Chakravarti, A.; Robe, P.; Zhai, G.; Chakladar, A.; Loeffler, J.; Black, P.; Frank, D.A. A STAT3 Gene Expression Signature in Gliomas is Associated with a Poor Prognosis. Transl. Oncogenom. 2007, 2, 99-105. [CrossRef]

71. Hurtt, M.R.; Moossy, J.; Donovan-Peluso, M.; Locker, J. Amplification of epidermal growth factor receptor gene in gliomas: Histopathology and prognosis. J. Neuropathol. Exp. Neurol. 1992, 51, 84-90. [CrossRef]

72. Camara-Quintana, J.Q.; Nitta, R.T.; Li, G. Pathology: Commonly monitored glioblastoma markers: EFGR, EGFRvIII, PTEN, and MGMT. Neurosurg. Clin. N. Am. 2012, 23, 237-246. [CrossRef]

73. Chen, X.C.; Wei, X.T.; Guan, J.H.; Shu, H.; Chen, D. EGF stimulates glioblastoma metastasis by induction of matrix metalloproteinase-9 in an EGFR-dependent mechanism. Oncotarget 2017, 8, 65969-65982. [CrossRef]

74. Lo, H.W.; Cao, X.; Zhu, H.; Ali-Osman, F. Constitutively activated STAT3 frequently coexpresses with epidermal growth factor receptor in high-grade gliomas and targeting STAT3 sensitizes them to Iressa and alkylators. Clin. Cancer Res. 2008, 14, 6042-6054. [CrossRef]

75. Lin, H.Y.; Huang, B.R.; Yeh, W.L.; Lee, C.H.; Huang, S.S.; Lai, C.H.; Lin, H.; Lu, D.Y. Antineuroinflammatory effects of lycopene via activation of adenosine monophosphate-activated protein kinase-alpha1/heme oxygenase-1 pathways. Neurobiol. Aging 2014, 35, 191-202. [CrossRef]

76. Lai, S.W.; Liu, Y.S.; Lu, D.Y.; Tsai, C.F. Melatonin Modulates the Microenvironment of Glioblastoma Multiforme by Targeting Sirtuin 1. Nutrients 2019, 11, 1343. [CrossRef]

77. Lai, S.W.; Huang, B.R.; Liu, Y.S.; Lin, H.Y.; Chen, C.C.; Tsai, C.F.; Lu, D.Y.; Lin, C. Differential Characterization of Temozolomide-Resistant Human Glioma Cells. Int. J. Mol. Sci. 2018, 19, 127. [CrossRef]

78. Lai, S.W.; Chen, J.H.; Lin, H.Y.; Liu, Y.S.; Tsai, C.F.; Chang, P.C.; Lu, D.Y.; Lin, C. Regulatory Effects of Neuroinflammatory Responses Through Brain-Derived Neurotrophic Factor Signaling in Microglial Cells. Mol. Neurobiol. 2018, 55, 7487-7499. [CrossRef]

79. Chuang, J.Y.; Tsai, C.F.; Chang, S.W.; Chiang, I.P.; Huang, S.M.; Lin, H.Y.; Yeh, W.L.; Lu, D.Y. Glial cell line-derived neurotrophic factor induces cell migration in human oral squamous cell carcinoma. Oral Oncol. 2013, 49, 1103-1112. [CrossRef]

(C) 2020 by the authors. Licensee MDPI, Basel, Switzerland. This article is an open access article distributed under the terms and conditions of the Creative Commons Attribution (CC BY) license (http://creativecommons.org/licenses/by/4.0/). 